Research Article

\title{
Bending Capacity of Concrete-Encased Underground Electrical Duct Banks under Monotonic Loading: An Experimental Study
}

\author{
Ting-jin Liu $\mathbb{D}^{1,2,3}$ Liang-yi Cai, ${ }^{3}$ Qiang Liao, ${ }^{3}$ and Yu-bing Yang ${ }^{4}$ \\ ${ }^{1}$ South China Institute of Geotechnical Engineering, South China University of Technology, Guangzhou 510640, \\ Guangdong, China \\ ${ }^{2}$ State Key Laboratory of Subtropical Building Science, South China University of Technology, Guangzhou 510640, \\ Guangdong, China \\ ${ }^{3}$ School of Civil Engineering and Transportation, South China University of Technology, Guangzhou 510640, Guangdong, China \\ ${ }^{4}$ College of Water Conservancy and Civil Engineering, South China Agricultural University, Guangzhou 510642, \\ Guangdong, China
}

Correspondence should be addressed to Ting-jin Liu; liu_tingjin@163.com

Received 22 September 2020; Revised 9 December 2020; Accepted 21 December 2020; Published 23 January 2021

Academic Editor: Zhushan Shao

Copyright (C) 2021 Ting-jin Liu et al. This is an open access article distributed under the Creative Commons Attribution License, which permits unrestricted use, distribution, and reproduction in any medium, provided the original work is properly cited.

\begin{abstract}
The bending capacity of concrete-encased underground electrical duct banks has been the subject of considerable investigation using the load-structure method; however, the role of high-density polyethylene (HDPE) conduits and the thresholds of electrical duct banks has not been fully scrutinized. This study examines the bending behaviors of electrical duct banks subjected to monotonic vertical loading in a soil box using an advanced monitoring device to measure the conduit diameter change. An analysis of the experiment shows the effective role of HDPE conduits in improving the bending capacity of electrical duct banks. The results suggest $5 \%$ and $7.5 \%$ as the deformation rate thresholds with respect to the ultimate states of serviceability and bearing capacity, respectively. The threshold of the longitudinal curvature radius is determined to be $18000 \mathrm{~m}$. Finally, the evolution trends of the stress and deformation rates of HDPE conduits are recommended for the monitoring indexes and control standards of electrical duct banks.
\end{abstract}

\section{Introduction}

Overhead lines, underground cables, and substations are critical infrastructure components in electricity transmission. In the central urban area of Shanghai, the proportion of underground cables has exceeded $80 \%$ [1]. In London, most of the electricity supply is also transmitted via underground cables, which are traditionally found just below the road surface [2]. Cables can be laid under a road, across open land, or in tunnels. They operate at a range of voltages reaching $400 \mathrm{kV}$ [3]. In most cases, high-voltage underground cables are laid in a duct bank rather than being buried directly in the ground. Therefore, it is very important to guarantee the safety of these underground structures $[4,5]$. In a duct bank, electrical cables are typically laid out within polyvinyl chloride (PVC)/modified polypropylene
(MPP)/high-density polyethylene (HDPE) conduits that are bundled together. These groupings of conduits are often protected by concrete casings. PVC spacers are also used to separate the internal conduits from concrete walls, as shown in Figure 1. In general, all concrete-encased electric conduit duct banks contain steel reinforcement throughout their entire length. The reinforcing steel is installed longitudinally at each corner of a duct bank (in cross section) and along the top and bottom. Stirrups are also needed to hold the longitudinal steel in place during the placement of the concrete.

An investigation of four high-voltage cable lines $(110 \mathrm{kV} /$ $220 \mathrm{kV}$ ) of the Zhuhai Power Supply Bureau of Guangdong Province showed that $5.35 \mathrm{~km}$ of electrical duct bank was laid along a $15.25 \mathrm{~km}$ long line - a considerable proportion. Generally, an electrical duct bank is laid $1 \sim 3 \mathrm{~m}$ underground. Because of factors such as defects in early design, 


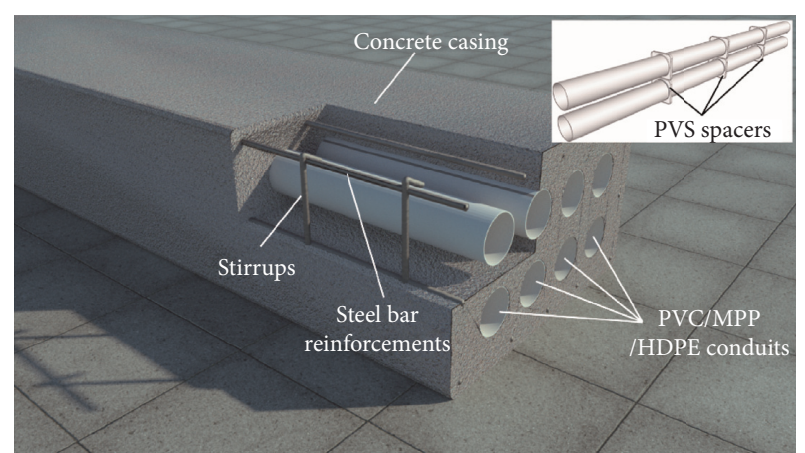

FIGURE 1: Sketch of concrete-encased underground electrical duct bank.

construction, and nearby infrastructure, deficiencies such as the differential settlement, tilting, and cracking of concrete and HDPE conduits can appear in electrical duct banks and working wells, as shown in Figure 2. Hence, protecting electrical cable duct banks and controlling their deformation and damage has become an important issue.

Most previous studies on electrical duct banks have focused on cable ampacity and thermal resistivity. Kelly et al. [6] provided a reference for various ampacity ratings that were dependent on installation. Nagley and Nease [7] conducted different installations to determine the relative thermal characteristics of two types of duct banks that differed in terms of duct spacing and the amount of concrete. Kellow [8-10] employed a numerical procedure to calculate the ampacity and rise in temperature rise and conducted experiments to study the ampacity of cables and the thermal performance of duct banks with and without forced cooling. El-Kady and Horrocks [11] described an efficient finite-element-based technique for calculating geometric factors for extended values of the external thermal resistance of cables in duct banks. Bascom [12] evaluated various cable and magnetic shielding configurations to minimize the resulting magnetic fields in an underground cable system along duct banks and near manholes. Hwang [13] described a combined magnetothermal analysis for calculating the thermal fields of a cable duct bank taking into account the effects of structural steels. Malmedal et al. [14] determined the effects of concrete mixtures on the resulting thermal resistivity. In addition, the optimization of cost and electrothermal performance has gradually become a research topic of interest. A multiobjective self-adaptive optimization method was proposed for the first time in 2018 to maximize ampacity and minimize the cost of underground cable duct banks [15]. Ocon et al. [16] used a modified Jaya algorithm to optimize the material costs and electrothermal performance of an underground power cable system (UPCS). Charerndee et al. [17] evaluated the effects of concrete duct bank dimensions and the thermal properties of concrete on the sensitivity of underground power cable ampacity.

When a duct bank deforms, the mechanical behaviors are key factors that affect the thermal performance and the magnetic fields. Experimental studies have been conducted to explore these mechanical behaviors. Liu et al. $[18,19]$ conducted small-scale experiments to study the flexural performance and shear bearing capacity of concrete cable ducts reinforced with GFRP bars. In general, research on electrical cable duct banks has mainly focused on cable ampacity, thermal resistivity, and the optimization of cost and electrothermal performance. Wang and Guo [20] carried out a numerical simulation and data analysis to assess the settlement and damage of a working shaft of an underground high-voltage electricity cable duct and determined the threshold of differential settlement. However, research on the mechanical behaviors and thresholds of deformation and damage has been limited.

This paper presents the results of an experimental investigation on concrete cable ducts subjected to monotonic vertical loading with a soil-structure method. An innovative displacement measuring device is used to measure the change in conduit diameter of HDPE conduits during the experiment. Previous tests have concentrated on the cover concrete and reinforcements and disregarded the HDPE conduits $[18,19]$. The experiment carried out within the framework of this study is unique in addressing the following objectives: (1) to study the role of HDPE conduits, (2) develop a set of thresholds for HDPE conduits, (3) study the bending behaviors of electrical duct banks, and (4) offer suggestions on monitoring indexes and control standards.

\section{Experimental Procedure}

2.1. Test Setup and Loading Protocol. The experimental program was based on a monotonic loading static test of four electrical duct banks. The test setup consisted of reaction frames made from hollow steel sections and a soil box providing lateral and vertical soil pressure. The electrical duct banks were tested vertically. Two hinge supports were set at the bottom of the soil box to prevent the excessive settlement of the specimens. The hinge supports were rectangular columns made of Q335 steel with dimensions of $800 \mathrm{~mm} \times 300 \mathrm{~mm} \times 300 \mathrm{~mm}$. The specimens were placed $200 \mathrm{~mm}$ above the supports. The physical and mechanical properties of the soil used in the experiment are given in Table 1. The soil box was made of Q235 steel and tempered glass with a size of $4.2 \mathrm{~m} \times 2.7 \mathrm{~m} \times 2.7 \mathrm{~m}$. An actuator was used to apply the load, and the load magnitude was measured by a force sensor. A load distributing beam was used to transfer the concentrated load into a distributed surface load. The test adopted monotonic static step loading, and the load of each stage was approximately $10 \mathrm{kN}$. When approaching the failure load, the loading mode was converted from force-control loading to displacement-control loading until a significant decrease in load appeared in the readings of the force sensor. The details of test setup are shown in Figure 3.

2.2. Test Specimens. Because the bending behaviors of the fullscale specimen and small specimen were similar [18], the specimens for the experiment were built with double conduits in different arrangements, section heights, and reinforcements. Figure 4 shows the configuration of the reinforcing bars, stirrups, concrete, and HDPE conduits in the specimen. The 


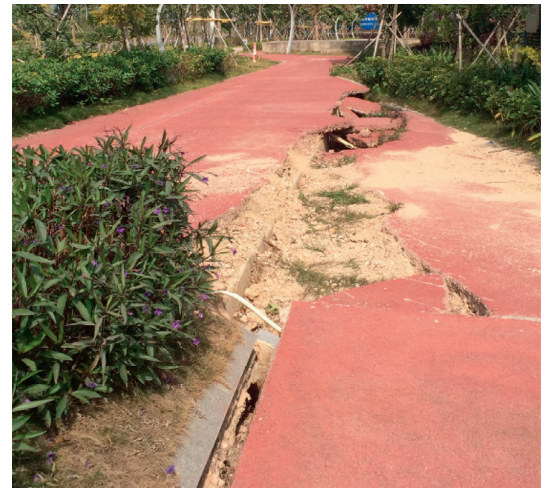

(a)

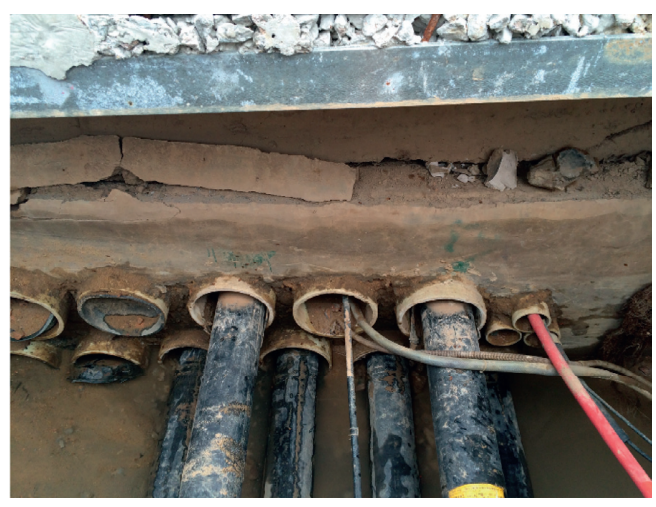

(b)

Figure 2: Ground subsidence (a) and damage (b) caused by deficiencies in concrete-encased underground electrical duct banks.

Table 1: Physical and mechanical properties of soil.

\begin{tabular}{lccccccc}
\hline $\begin{array}{l}\text { Wet density } \\
\rho\left(\mathrm{g} / \mathrm{cm}^{3}\right)\end{array}$ & $\begin{array}{c}\text { Water content } \\
\omega(\%)\end{array}$ & Cohesion c $(\mathrm{kPa})$ & $\begin{array}{c}\text { Friction } \\
\text { angle } \\
\varphi\left(^{\circ}\right)\end{array}$ & $\begin{array}{c}\text { Specific gravity } \\
\mathrm{G}_{\mathrm{s}}\end{array}$ & $\begin{array}{c}\text { Compression modulus } \\
\mathrm{E}_{\mathrm{s}}(\mathrm{MPa})\end{array}$ & $\begin{array}{c}\text { Liquid } \\
\text { limit } \\
\omega_{\mathrm{L}}\end{array}$ & $\begin{array}{c}\text { Plastic limit } \\
\omega_{\mathrm{P}}\end{array}$ \\
\hline 1.88 & 30.40 & 15 & 7.8 & 2.72 & 5.9 & 0.422 & 0.276 \\
\hline
\end{tabular}

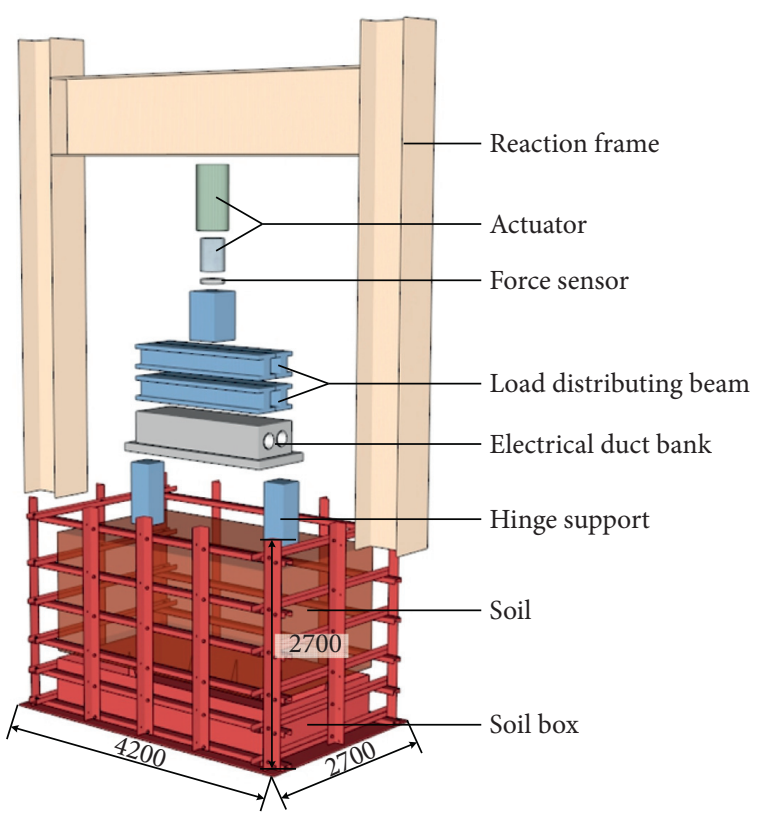

(a)

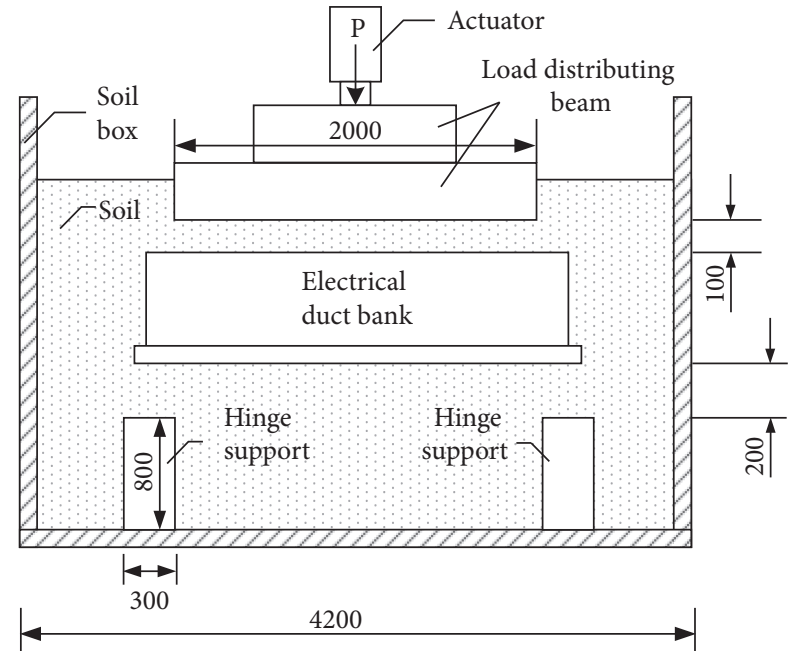

(b)

Figure 3: Continued. 


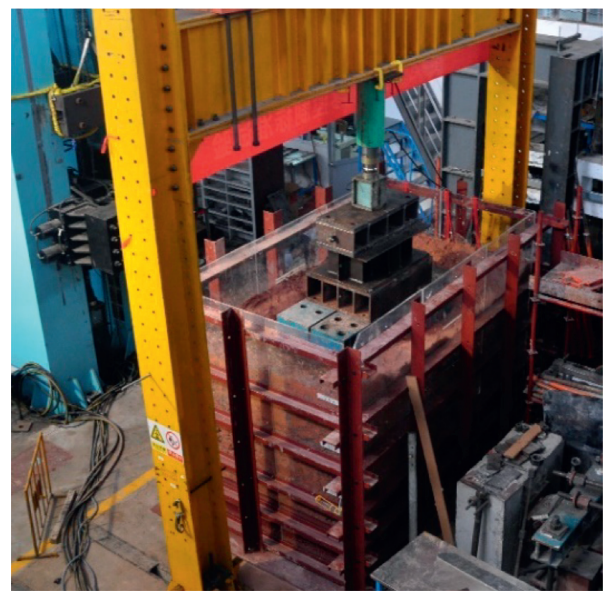

(c)

FIgURE 3: Test setup details (millimeters).

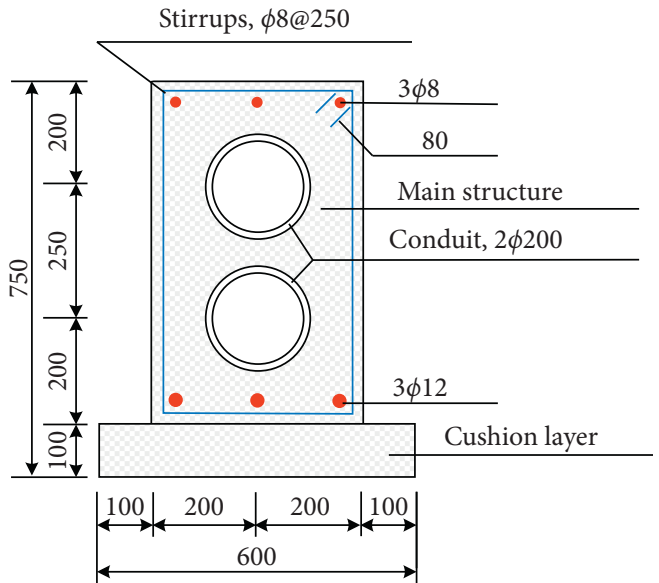

(a)

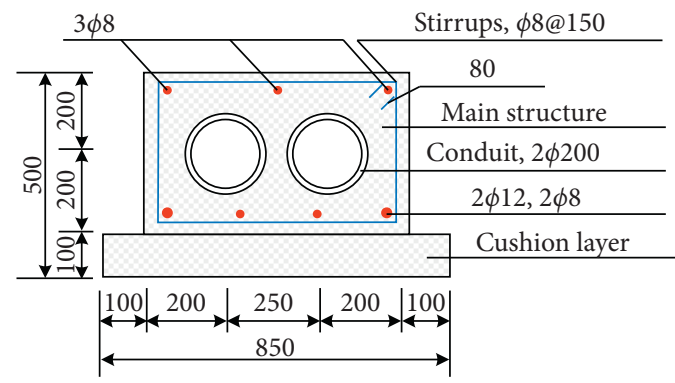

(c)

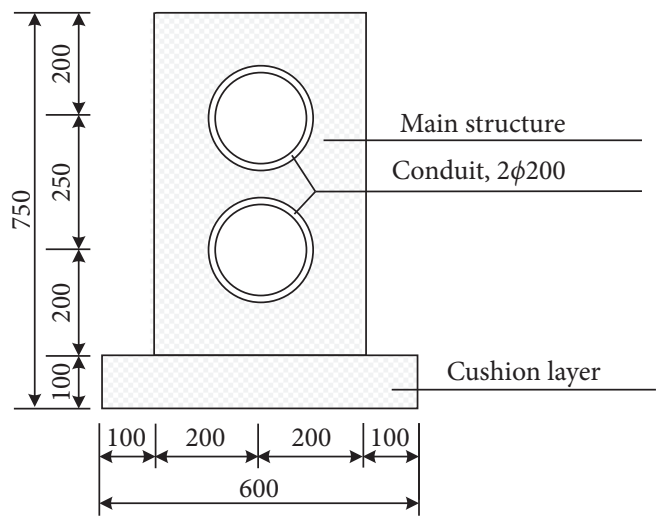

(b)

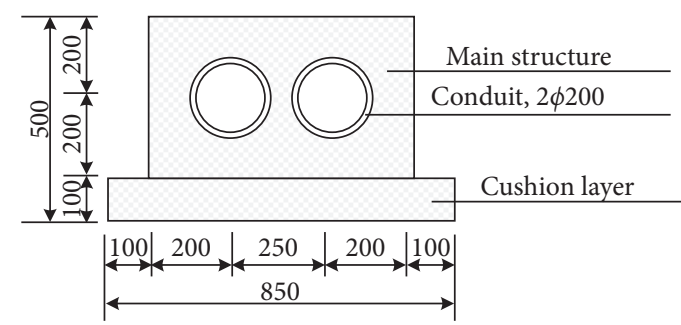

(d)

Figure 4: Test specimen arrangement (millimeters): (a) A1, (b) A2, (c) B1, and (d) B2.

geometric dimensions and reinforcement specifications for the specimens are shown in Table 2. For A-type specimens, the section height of the main structure was $650 \mathrm{~mm}$, and the conduits were laid vertically, while B-type specimens were $400 \mathrm{~mm}$, and the conduits were laid horizontally. Specimens A1 and $\mathrm{B} 1$ were reinforced, but there were no rebars in $\mathrm{A} 2$ and $\mathrm{B} 2$. The reinforcing rebars in specimens A1 and B1 were HRB335 with diameters of $8 \mathrm{~mm}$ and $12 \mathrm{~mm}$. The stirrups for A1 and B1 were closed with $135^{\circ}$ hooks on both ends. The compressive strength values of concrete $f_{\text {ck }}$ in the main structure and cushion layer were $21.2 \mathrm{MPa}$ and $10.0 \mathrm{MPa}$, respectively; the tensile strength values $\mathrm{f}_{\mathrm{tk}}$ were $2.43 \mathrm{MPa}$ and $1.15 \mathrm{MPa}$; the elastic modulus values $E_{\mathrm{c}}$ were $25.5 \mathrm{GPa}$ and $17.5 \mathrm{GPa}$. The yield strength values $\sigma_{\mathrm{y}}$ of HPB300 and HRB335 were $300 \mathrm{MPa}$ and $335 \mathrm{MPa}$, respectively; the ultimate strength values $\sigma_{\mathrm{u}}$ of HPB300 and HRB335 were $420 \mathrm{MPa}$ and $455 \mathrm{MPa}$, respectively; the elastic modulus values $E_{\mathrm{f}}$ were $200 \mathrm{GPa}$ and $210 \mathrm{GPa}$. The HDPE conduits were made of high-density polyethylene 
TABLe 2: Geometric dimensions and reinforcement specifications for specimens.

\begin{tabular}{lcccccc}
\hline Specimen & $B(\mathrm{~mm})$ & $H(\mathrm{~mm})$ & $D(\mathrm{~mm})$ & Conduit layout & $\begin{array}{c}\text { Longitudinal } \\
\text { bars (HRB335) }\end{array}$ & Stirrups (HPB300) \\
\hline A1 & 400 & 650 & 200 & $2 \times 1$ & $\begin{array}{c}\text { Top: } 3 \varphi 8 \\
\text { Bottom: } 3 \varphi 12\end{array}$ & 0 \\
A2 & 400 & 650 & 200 & $2 \times 1$ & 0 & 0 \\
B1 & 650 & 400 & 200 & $1 \times 2$ & Top: $3 \varphi 8$ & 0 \\
B2 & 650 & 400 & 200 & $1 \times 2$ & Bottom: $2 \varphi 12 \& 2 \varphi 8$ & 0 \\
\hline
\end{tabular}

Notes. B: section width of main structure; H: section height of main structure; D: diameter of conduit; $3 \varphi 8$ : three $8 \mathrm{~mm}$ longitudinal bars; $\varphi 8 @ 150: 150 \mathrm{~mm}$ distance between $8 \mathrm{~mm}$ stirrups.

(HDPE) with a $200 \mathrm{~mm}$ outside diameter and $10 \mathrm{~mm}$ thickness. The tension strength value $f_{\mathrm{tp}}$ was $18 \mathrm{MPa}$. The elastic modulus value $E_{\mathrm{p}}$ was $800 \mathrm{MPa}$. PVC spacers were set every $0.5 \mathrm{~m}$ along the longitudinal direction.

2.3. Monitoring System. Accurate monitoring technologies play an important role in physical experiments. In this study, the change in conduit diameter was a key factor. Thus, a conduit diameter-change measuring device was employed to measure the diameter change of the HDPE conduits, which could replicate the deformation behaviors inside the conduits. Figure 5 shows details of the conduit diameter-change measuring device.

The conduit diameter-change measuring device was provided with two round limit disks at both ends that matched the inner diameter of the measured conduits to ensure that there was no relative displacement between the measuring device and the measured conduits. Between the two limit disks, two fixed round disks with four displacement gauges installed orthogonally were used to measure the displacement change of the quarter-span and midspan of the measured conduits. To ensure the stability of the fixed round disks and the accuracy of the measuring points, the round disks and limit disks were connected in series on one steel rod. Thus, there was little relative slip or shedding between the device and the conduits.

In addition, there are other monitoring devices shown in Table 3. Soil pressure cells were used to record the soil pressure variation during the loading process. Strain gauges were used to measure the strain of the cover concrete, reinforcements, and HDPE conduits. Displacement gauges were used to measure the overall displacement of the specimens. The positions of the measuring points are shown in Figure 6. Note that the data of numbered measuring points were analyzed and those without numbers were either lost or unreasonable.

\section{Results and Discussion}

3.1. Damage Pattern. Figure 7 shows the load-displacement curve. Due to improper instrument operation, the loaddisplacement curve of specimen B1 was lost. As shown in Figure 7, the failure loads of specimens A1, A2, and B2 are $1275 \mathrm{kPa}, 900 \mathrm{kPa}$, and $400 \mathrm{kPa}$, respectively. Specimen A1 contains the reinforcements, while A2 does not. Specimen A2 has a higher section height than specimen B2. Hence, it can be concluded that the reinforcements and higher section height have an effect on improving the bending capacity and the section height may be a larger contributor than the reinforcements. After the failure load, a steep load drop appears in $\mathrm{A} 1$, but the load drops in $\mathrm{A} 2$ and $\mathrm{B} 2$ are gentle. In addition, the midspan deflections of $\mathrm{A} 1, \mathrm{~A} 2$, and $\mathrm{B} 2$ are close within the range of $60 \mathrm{~mm} \sim 80 \mathrm{~mm}$. Although the bending capacity of the specimens differs greatly, their midspan deflections are close. Furthermore, a visible yield stage can be seen in A1, while no yield stage can be seen in A2. Thus, it can be speculated that the reinforcements cause the yield stage. The displacement of B2 shows an approximately linear increase without a yield stage, which means that B2 underwent brittle failure.

Figure 8 shows the damage patterns of the four specimens. The main cracks of specimens A2, B1, and B2 appear at the midspan, while the main crack of A1 is a diagonal crack that appears near the left hinge support. The main crack widths in the main structure of $\mathrm{A} 1, \mathrm{~A} 2, \mathrm{~B} 1$, and $\mathrm{B} 2$ are approximately $10 \mathrm{~mm}, 40 \mathrm{~mm}, 25 \mathrm{~mm}$, and $20 \mathrm{~mm}$, respectively. In addition, there are other secondary cracks. For specimen A1, there is one $4 \mathrm{~mm}$ diagonal crack near the left support and one $3 \mathrm{~mm}$ vertical crack at the midspan. For specimen A2, the main crack is split into one $10 \mathrm{~mm}$ crack and one $20 \mathrm{~mm}$ crack extending to the top of the main structure. For specimen B1, one $8 \mathrm{~mm}$ crack appears $180 \mathrm{~mm}$ to the left of the main crack. For specimen B2, the main crack is split into one $2 \mathrm{~mm}$ crack and one $10 \mathrm{~mm}$ crack extending to the top of the main structure. Furthermore, the concrete on the compression side is crushed in the A-type specimens, while no crushing is found in the B-type specimens. In summary, it can be seen that the damage pattern of specimens A2, B1, and B2 is similar to that of simply supported beams.

3.2. Soil Pressure. Figures 9(a) and 9(b) show the arrangement of measuring points. As shown in Figures 7 and 9(c), the curve of the $1 / 2$-bottom soil pressure evolution is similar to the load-displacement curve. For example, when the load is $0 \sim 400 \mathrm{kPa}$, the displacement and soil pressure of A1 increase approximately linearly, after which a yield stage appears. This means that as the displacement increases, the soil is compacted, and then the soil pressure provided to the specimen is increased. Thus, the increase in displacement and soil pressure can be considered to occur almost simultaneously. As shown in Figure 9(c), the maximum 1/2bottom soil pressures of the four specimens are close within 


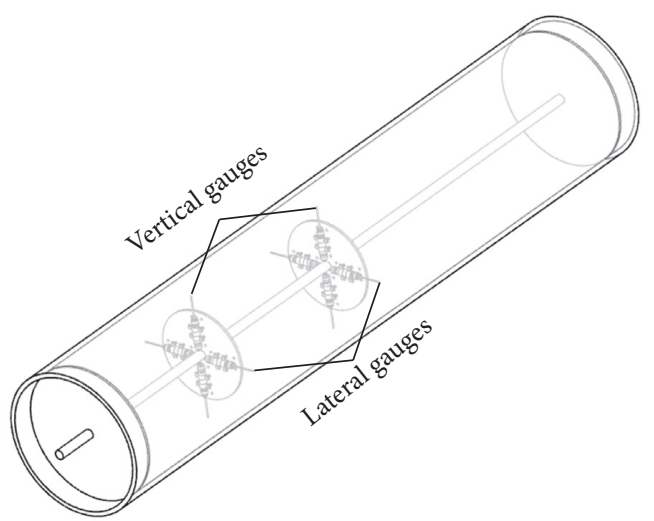

(a)

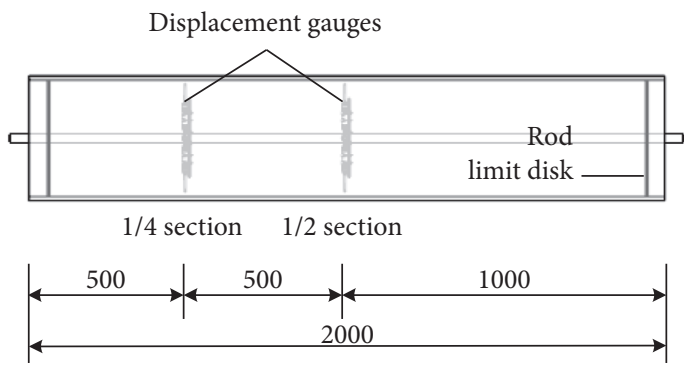

(b)

Figure 5: Conduit diameter-change measuring device. (a) Perspective drawing. (b) Elevation.

TABle 3: Monitoring system.

Monitoring devices

Strain gauges

Soil pressure cells

Force sensor

Displacement gauges

Conduit diameter-change measuring device

Monitoring object

Length change

Soil pressure in soil stratum

Applied force

Displacement of specimens

Diameter change
Precision $\leq 1.0 \%$ FS $\leq 1.0 \%$ FS $\leq 0.5 \%$ FS $\leq 0.5 \% \mathrm{FS}$ $\leq 0.5 \%$ FS

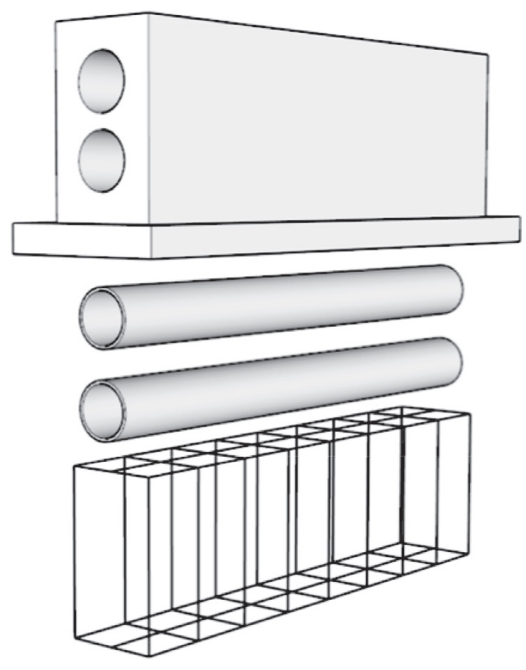

(i)

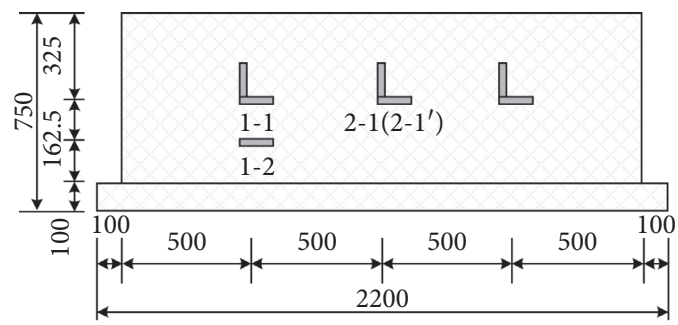

(i)

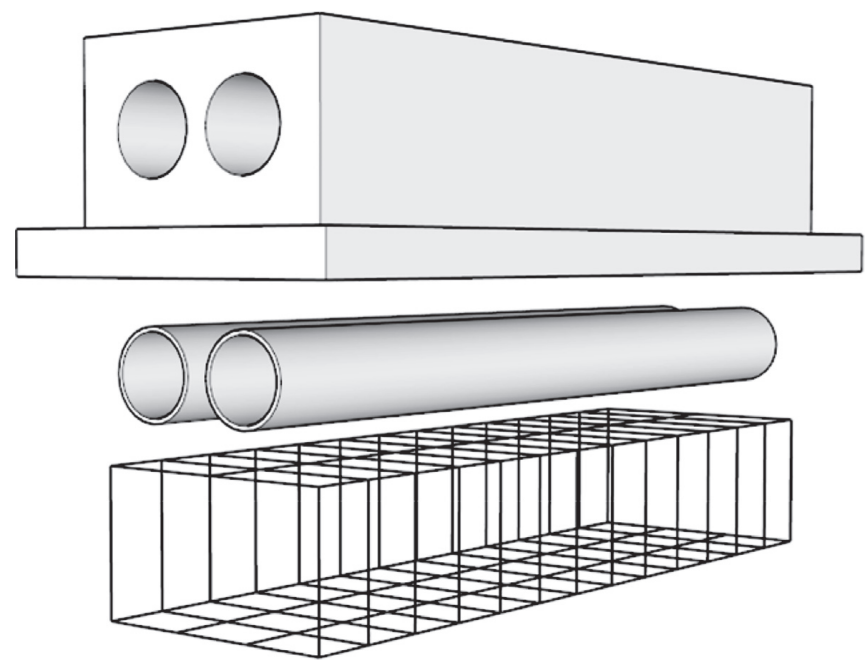

(ii)

(a)

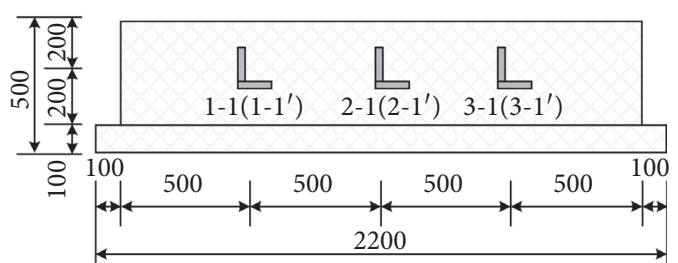

(ii)

(b)

Figure 6: Continued. 


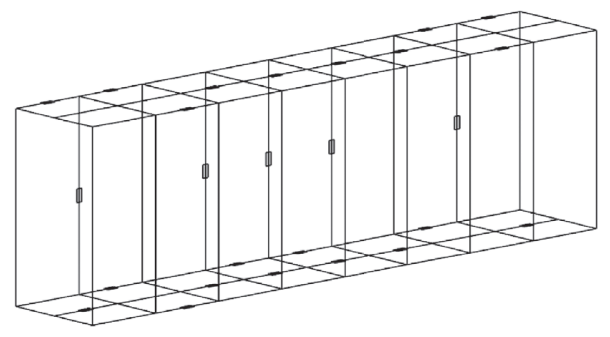

(i)

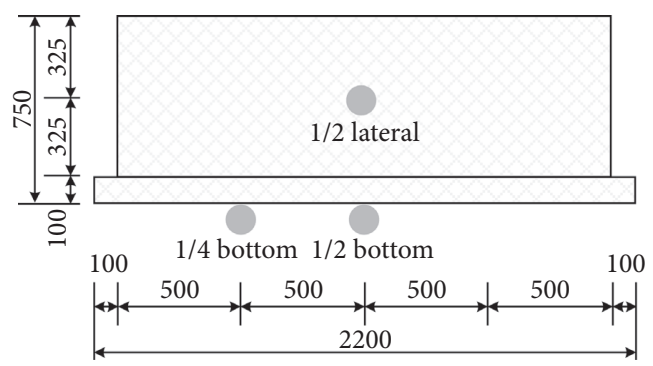

(i)

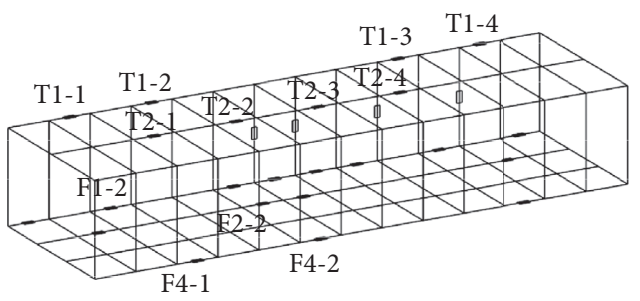

(ii)

(c)

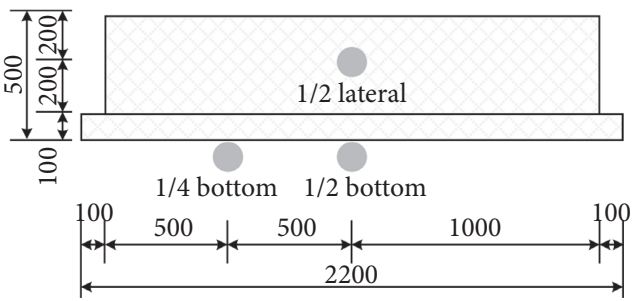

(ii)

(d)
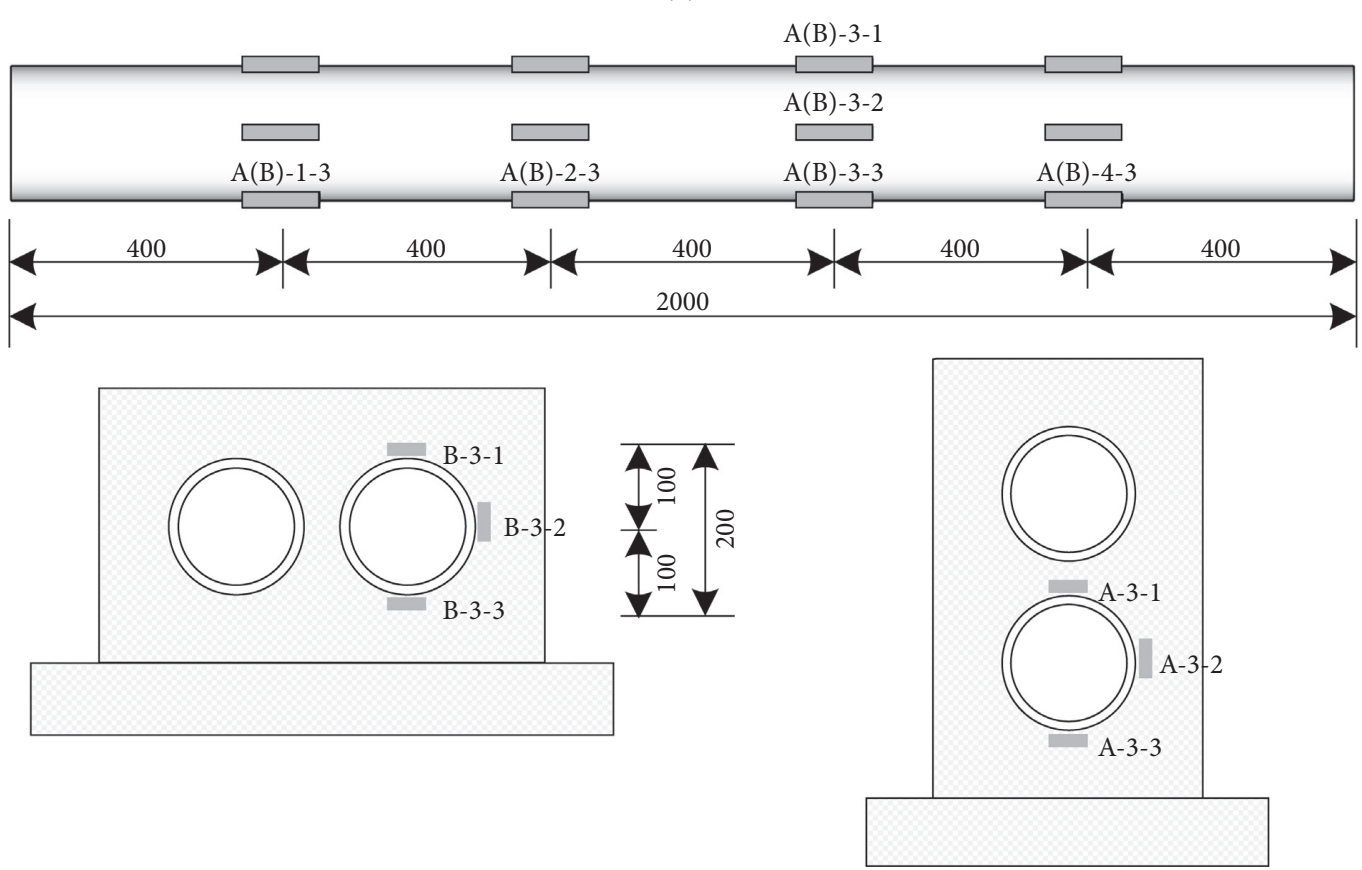

(e)

FIGURE 6: Specimen diagram and measurement points in the experiment (millimeters). (a) Specimen diagram: (i) A-type and (ii) B-type. (b) Cover concrete: (i) A-type and (ii) B-type. (c) Reinforcements: (i) A-type and (ii) B-type. (d) Soil pressure: (i) A-type and (ii) B-type. (e) HDPE conduits.

a range of $140 \mathrm{kPa} \sim 160 \mathrm{kPa}$. Figure $9(\mathrm{~d})$ shows that the maximum 1/4-bottom soil pressures of $\mathrm{A} 1, \mathrm{~A} 2$, and $\mathrm{B} 2$ are within a range of $80 \mathrm{kPa} \sim 130 \mathrm{kPa}$. The maximum of the $1 / 4-$ bottom soil pressure is less than that of the 1/2-bottom soil pressure. However, as shown in Figure 9(e), the maximum soil pressures at the $1 / 2$ lateral side are approximately $10 \mathrm{kPa}$, which are much less than the maximum soil pressures at the bottom. The cause might be that the soil on the lateral side was not under proper compaction during the experiment.

\subsection{Strain or Stress Analysis}

3.3.1. Cover Concrete. As shown in Figure 10(a), measuring points A-1-1, A-2-1, and A-2-1' (' representing the back side) were arranged at a height of $1 / 2 \mathrm{H}$, and $\mathrm{A}-1-2$ was arranged at height of $1 / 4 \mathrm{H} ; \mathrm{A}-1-1$ and $\mathrm{A}-1-2$ were arranged at a $1 / 4$ span; A-2-1 and A-2-1' were arranged at a $1 / 2$ span. Figure 10(b) shows the strain curve of the cover concrete. As shown in Figure 10(b), all the strains are tensile strains. 


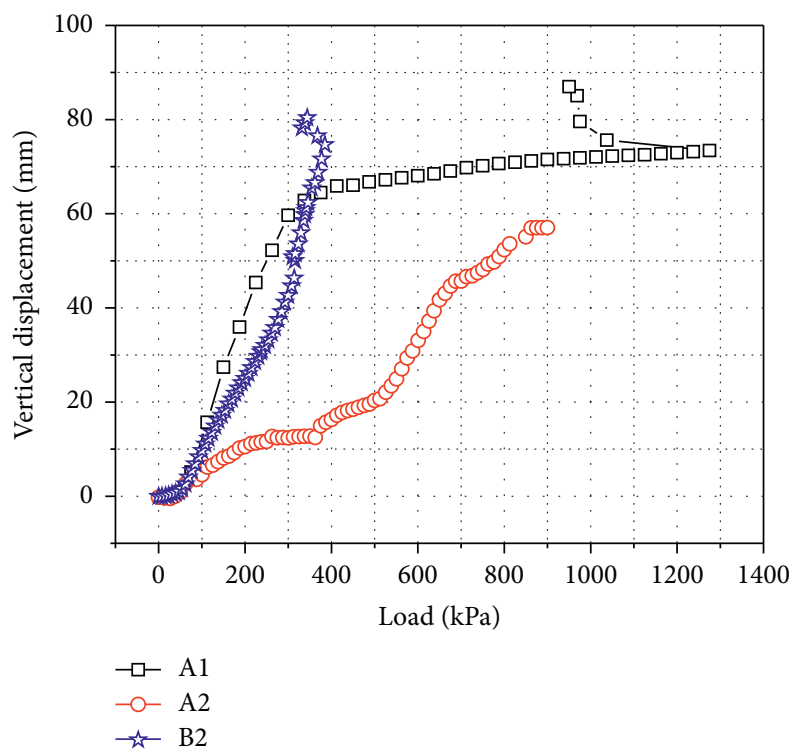

Figure 7: Load-displacement curve.
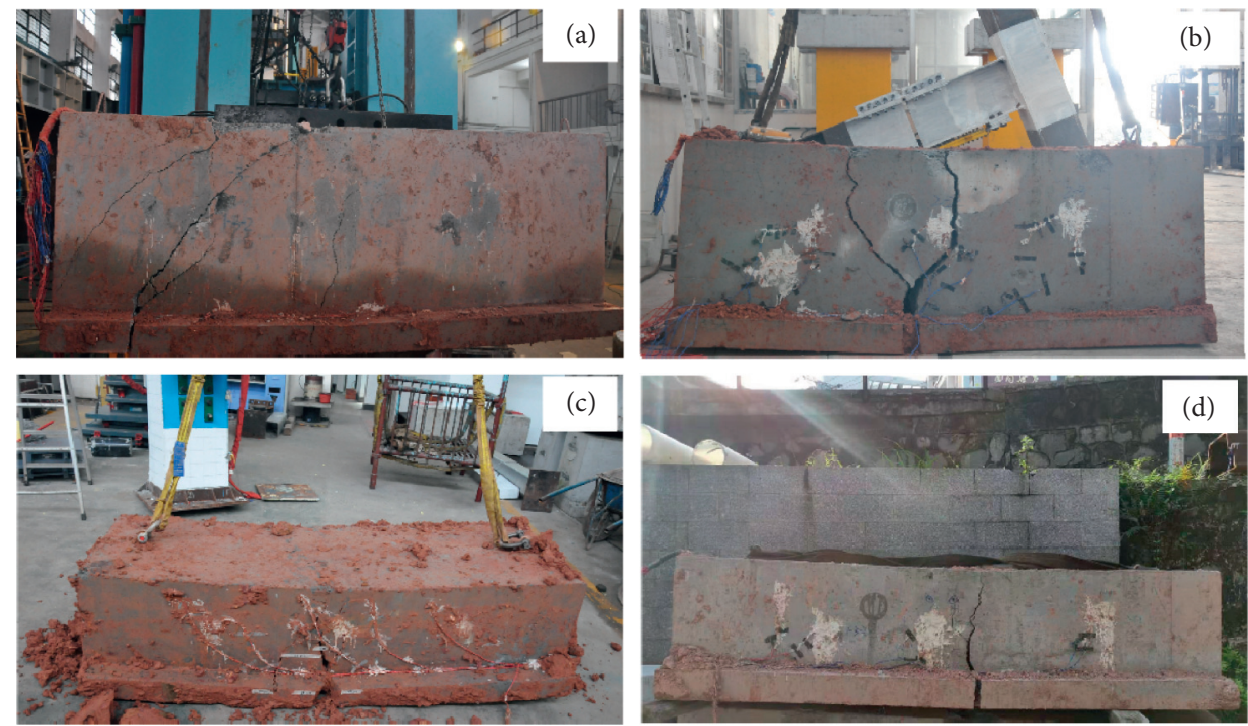

Figure 8: Damage patterns: (a) for A1, (b) for A2, (c) for B1, and (d) for B2.

When the load is less than $375 \mathrm{kPa}$, the strain barely increases. When the load exceeds $375 \mathrm{kPa}$, the strains of A-1-2, A-2-1, and A-2-1' are larger than the tensile cracking strain $(100 \mu \varepsilon)$, which means that cracks appear at $1 / 2 \mathrm{H}$ of the $1 / 2$ span and $1 / 4 \mathrm{H}$ of the $1 / 4$ span. When the load reaches $500 \mathrm{kPa}$, the strain of A-1-1 exceeds $100 \mu \varepsilon$; hence, cracks appear at $1 / 2 \mathrm{H}$ of the $1 / 4$ span. Thus, it can be inferred that cracks extend from $1 / 4 \mathrm{H}$ to $1 / 2 \mathrm{H}$ at the $1 / 4$ span when the load increases from $375 \mathrm{kPa}$ to $500 \mathrm{kPa}$. In the meantime, the neutral axis moves upwards, and the crack width starts to grow after the strain exceeds $100 \mu \varepsilon$. Furthermore, a visible inflection point appears in the four curves. The inflection points of A-2-1, A-2-1', A-1-2, and A-1-1 appear at loads of $375 \mathrm{kPa}, 551 \mathrm{kPa}, 701 \mathrm{kPa}$, and $763 \mathrm{kPa}$, which corresponds to the maximum crack width.
As shown in Figure 11(b), measuring points B-1-1, B-2$1^{\prime}$, and B-3-1' (' representing the back side) are arranged at a height of $1 / 2 \mathrm{H}$ at lengths of $1 / 4$ span, $1 / 2$ span, and 3/4 span, respectively. As shown in Figure 11(a), when the load reaches $300 \mathrm{kPa}$, the tensile strain of $\mathrm{B}-1-1$ reaches $100 \mu \varepsilon$. When the load exceeds $400 \mathrm{kPa}$, the tensile strain of $\mathrm{B}-2-1^{\prime}$ is larger than $100 \mu \varepsilon$. Hence, it can be speculated that the cracks at the $1 / 4$ span and $1 / 2$ span appear at loads of $300 \mathrm{kPa}$ and $400 \mathrm{kPa}$, respectively. The strain of $\mathrm{B}-3-1^{\prime}$ is considered compressive strain during the experiment. Because the compressive strain of B-3-1' does not exceed the compressive cracking strain $(1470 \mu \varepsilon)$, there are no cracks at approximately $1 / 2 \mathrm{H}$ of the $3 / 4$ span. The maximum crack widths of B-2-1' and B-1-1 appear at loads of $462 \mathrm{kPa}$ and $504 \mathrm{kPa}$, respectively. 


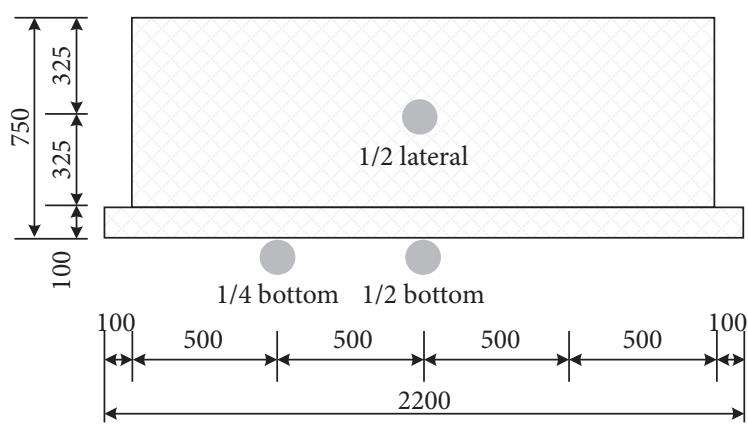

(a)

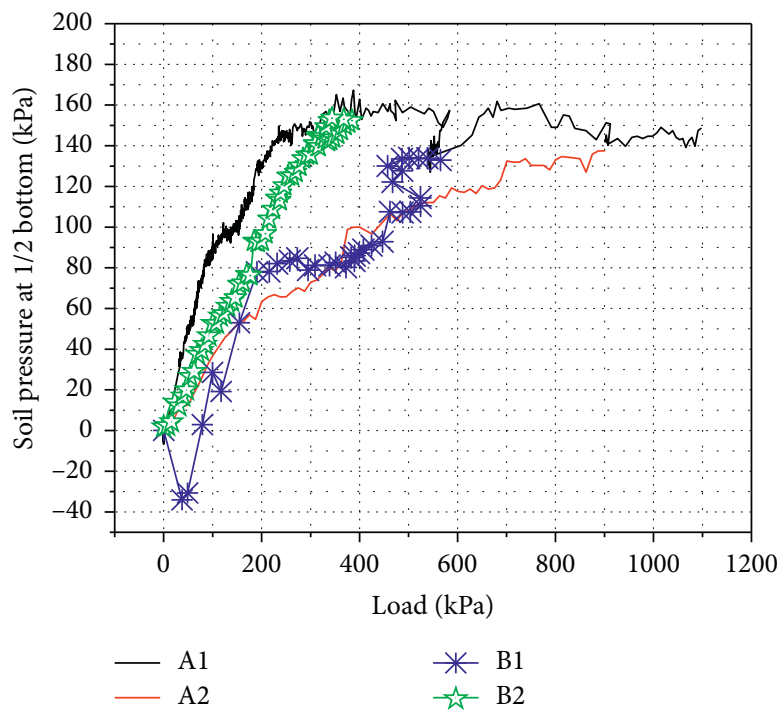

(c)

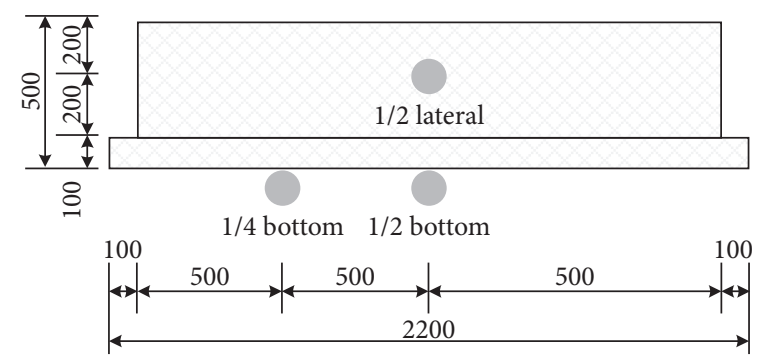

(b)

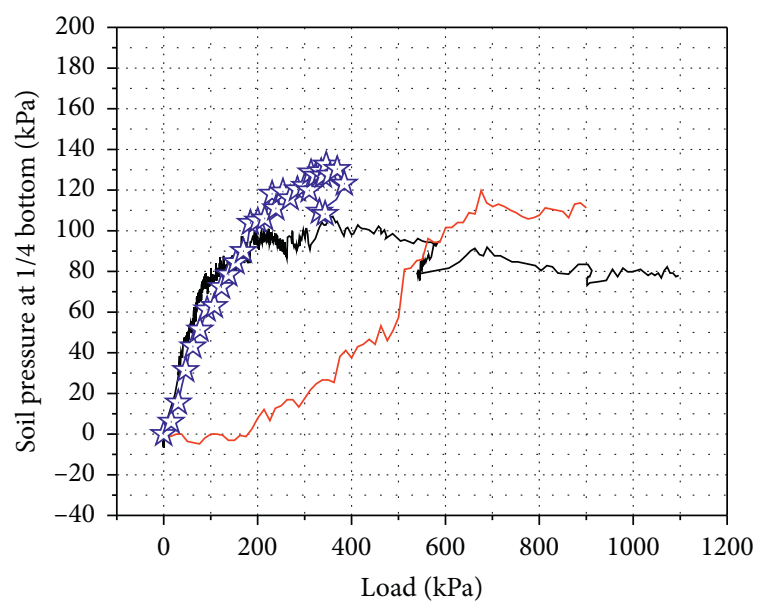

$\begin{array}{ll}- & \text { A1 } \\ - & \text { A2 } \\ - & \text { B2 }\end{array}$

(d)

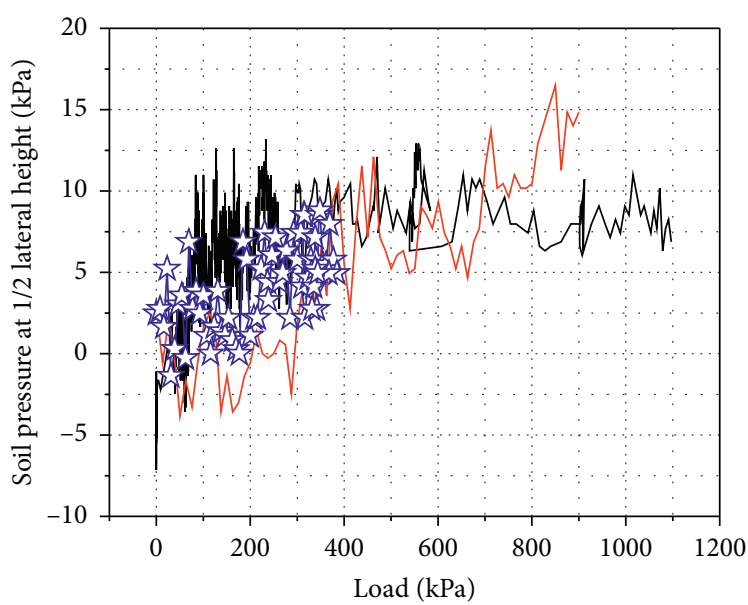

$-\mathrm{A} 1$
$-\mathrm{A} 2$
$\rightarrow \mathrm{B} 2$ 


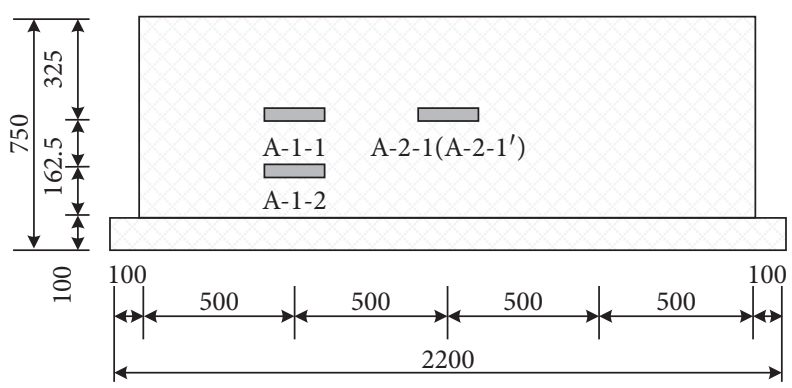

(a)
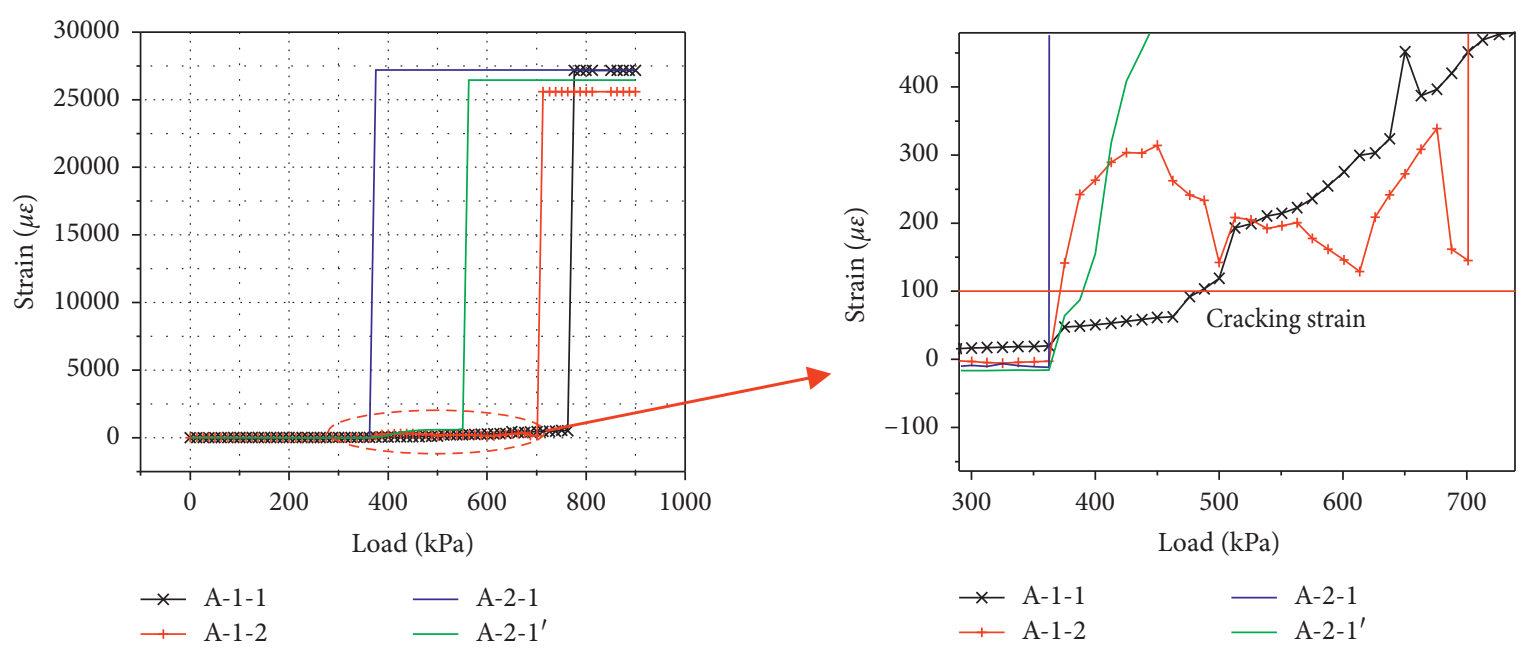

(b)

Figure 10: Strain evolution of A2. (a) Measuring points of cover concrete. (b) Load-strain curve.

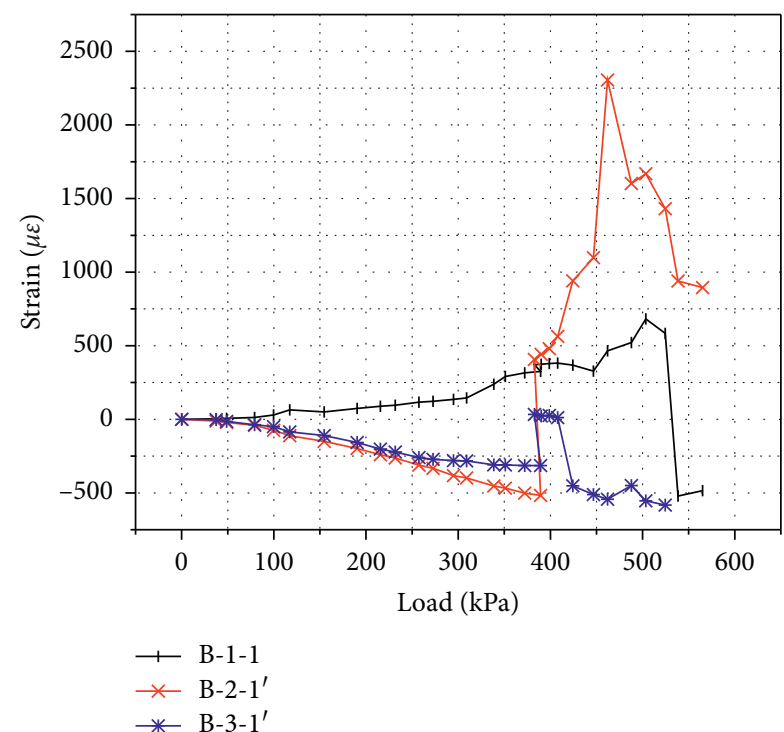

(a)

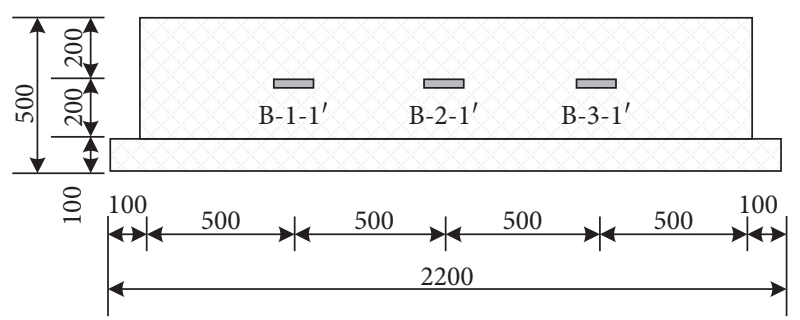

(b)

FIgURE 11: Strain evolution of B1. (a) Load-strain curve. (b) Measuring points of cover concrete.

stress starts to decrease. When the load approaches $525 \mathrm{kPa}$, the stress becomes tense. Then, the stress becomes larger than the yield stress at a load of $539 \mathrm{kPa}$, which means that the top rebar T2 yielded.
As shown in Figure 11(a) and 12(a), when the load is within a range of $0 \sim 400 \mathrm{kPa}$, the strain in the concrete and the stresses in the top rebar increase linearly. Cracks at the $1 /$ 2 span appear at a load of $400 \mathrm{kPa}$. Then, the neutral axis 


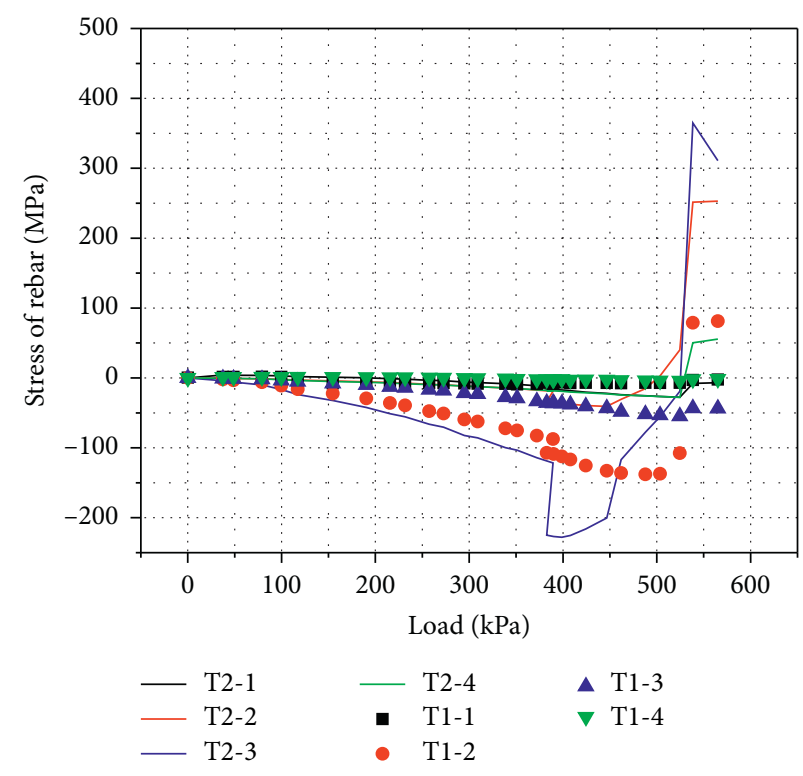

(a)

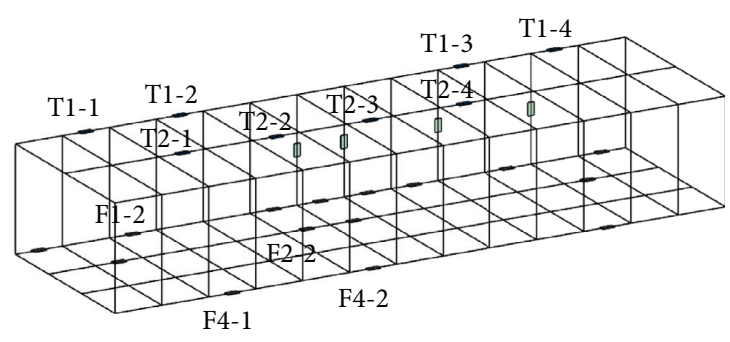

(b)

Figure 12: Stress evolution of B1. (a) Load-stress curve of top rebars. (b) Measuring points of rebars.

moves upwards. In the meantime, the crack width keeps growing. The maximum crack width of $1 / 2 \mathrm{H}$ at the $1 / 4$ span and $1 / 2$ span appears at loads of $462 \mathrm{kPa}$ and $504 \mathrm{kPa}$. It can be inferred that the concrete below $1 / 2 \mathrm{H}$ of the midspan is out of work at $504 \mathrm{kPa}$. Then, a steep drop in strain appears. The cause of the steep drop may be the bonding failure between the strain gauges and cover concrete due to the development of cracks. When the load reaches $525 \mathrm{kPa}$, the neutral axis moves above the top rebars, and the stresses become tense. Then, the rebar T2 yields at a load of $539 \mathrm{kPa}$. Because the crack at midspan extends to the compression zone and the top rebars yield, $539 \mathrm{kPa}$ can be considered the failure load.

As shown in Figure 12(b), measuring points F1-2, F2-2, F4-1, and F4-2 are arranged on the bottom rebar of specimen $\mathrm{B} 1$. When the load is less than $400 \mathrm{kPa}$, the stresses barely increase. When the load reaches $400 \mathrm{kPa}$, the tensile stress of F1-2 and F2-2 increases steeply, reaching the yield strength. This indicates that the bottom rebars yielded. In the meantime, a crack develops from the bottom to a height of $1 /$ 2 at the midspan. Thus, it can be speculated that the failure mode is brittle because the bottom rebar yields in a short time and midspan cracks develop rapidly. At a failure load of $539 \mathrm{kPa}$, the stresses of $\mathrm{F} 1-2$ remain at $455 \mathrm{MPa}$, and the stresses of F2-2 exceed $455 \mathrm{MPa}$, which means that rebars F1 and F2 reached the ultimate strength.

As seen from the analysis in Sections 3.3.1 and 3.3.2, the bending behaviors of the concrete and reinforcements are similar to those of the simply supported beam.

3.3.3. HDPE Conduit. As shown in Figure 13(a), measuring points A (B)-3-1, A (B)-3-2, and A (B)-3-3 are arranged on the same transverse section; $\mathrm{B}-1-3, \mathrm{~B}-2-3, \mathrm{~B}-3-3$, and $\mathrm{B}-4-3$ are arranged on the same profile. As shown in Figure 13(b), when the load is less than $300 \mathrm{kPa}$, the stresses barely increase. When the load exceeds $300 \mathrm{kPa}$, the stresses start to increase linearly. Then, the stresses of A2 and B2 undergo a sharp increase at loads of $500 \mathrm{kPa}$ and $350 \mathrm{kPa}$, respectively, exceeding the tensile strength of the conduit $(18 \mathrm{MPa})$. As shown in Figure 13(c), when the load exceeds $400 \mathrm{kPa}$, the stresses start to increase linearly. Similarly, the stress of B1 exceeds the tensile strength at a load of $525 \mathrm{kPa}$. The three curves have the same evolution trend, which is similar to that of the bottom rebar F1 given in Figure 14.

As shown in Figures 13(c) and 14, rebar F1 yields at a load of $400 \mathrm{kPa}$, and, at the same time, the stress of the conduit starts to increase. As shown in Figures 13(c) and 12(a), the stress of the conduit exceeds the tensile strength at a load of $525 \mathrm{kPa}$, and rebar T2 exceeds the yield strength at a load of $539 \mathrm{kPa}$. During the upward movement of the neutral axis, the stresses of rebar F1, the HDPE conduit, and rebar T2 exceed their designed tensile strengths. Thus, it can be inferred that HDPE conduits serve as the rebars during the experiment. Moreover, the stresses of different measuring points on the same conduit are close.

3.4. Vertical Deformation of HDPE Conduits. When a vertical load is applied to the specimen, the HDPE conduits are compressed vertically and stretched horizontally. Because the vertical compressive deformation may affect the cable inside the conduits and the horizontal tensile deformation has little effect on the cable, the vertical deformation should be studied. To describe the deformation of HDPE conduits, the deformation rate of the conduit vertical diameter is introduced [21]: 

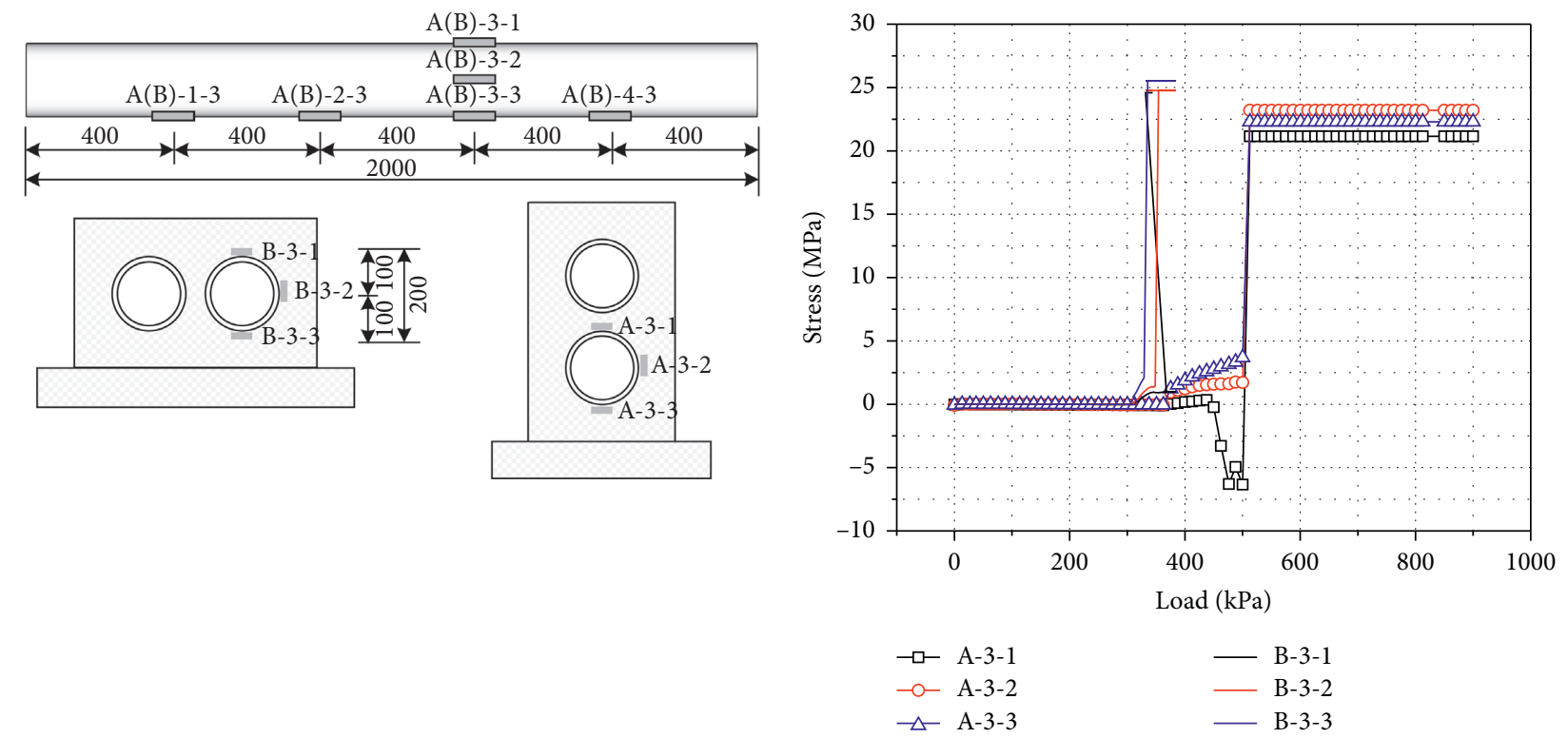

(a)

(b)

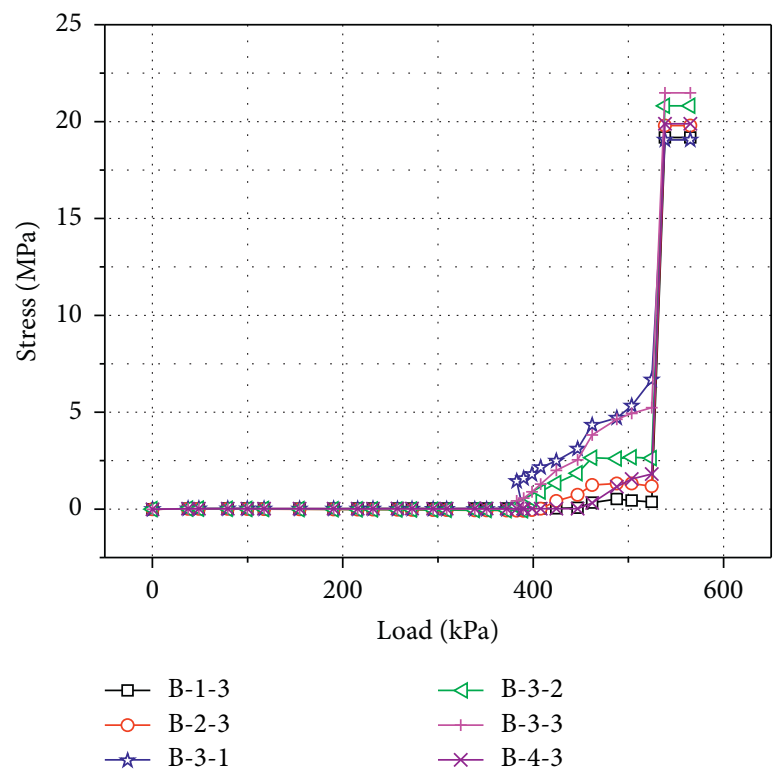

(c)

FIGURE 13: Stress evolution of HDPE conduits. (a) Measuring points of HDPE conduits. (b) Load-stress curve of A2 and B2. (c) Load-stress curve of B1.

$$
\varepsilon=\frac{W_{d, \max }}{D} \times 100 \%
$$

$W_{d, \max }:$ maximum deformation of the conduit vertical diameter

$D$ : outer diameter of conduit

$\varepsilon$ : deformation rate of conduit vertical diameter

As shown in Figure 15(a), the measuring points are arranged on a $1 / 2$ section and $1 / 4$ section of the conduit. As shown in Figure 15(b), the compressive deformation of A1 and $\mathrm{B} 1$ at the midpoint exceeds $10 \mathrm{~mm}$ (5\% conduit diameter), while B2 is below 5\%; the compressive deformation of A1 exceeds $15 \mathrm{~mm}$ (7.5\% conduit diameter), while B1 is below $7.5 \%$. Moreover, a visible yield stage appears in the A-type specimens. As shown in Figure 15(c), the deformation rates of $\mathrm{A} 1$ (bottom conduit) and $\mathrm{A} 2$ (both conduits) are larger than $7.5 \%$; the compressive deformation of A2 (bottom conduit) reaches $30 \mathrm{~mm}$ (15\% of conduit diameter). Thus, it can be concluded that the deformation rate of $\mathrm{A} 2$ is larger than that of A1. For A-type specimens, the 


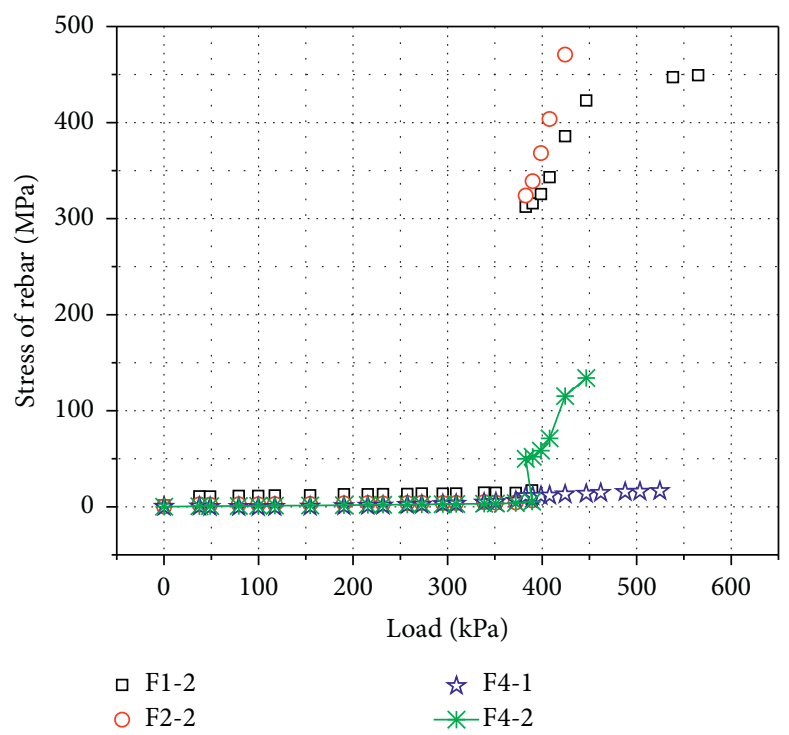

FIGURE 14: Load-stress curve of bottom rebars.

deformation rate of the bottom conduit is larger than that of the top conduit, which corresponds to the typical characteristics of bending specimens. The reason may be that the bottom conduit carries a larger bending moment and reaches the tensile strength earlier.

\section{Discussion}

4.1. Bending Capacity. The analysis in Section 3 shows that the bending characteristics of electrical duct banks are similar to those of simply supported beams. This section will discuss the bending capacity of the specimens during the experiment. First, HDPE conduits have a positive effect on improving the bending capacity of specimens, which can be found in Section 3.3.3. Hence, from the perspective of safety, the contribution of HDPE conduits can be neglected in the calculation of the bending capacity. The code [22] for the design of concrete structures in China gives the formulas for the design of the bending capacity of a normal section with holes. Thus, the bending capacity of the normal section of the concrete cable duct can be calculated according to the formulas in the code.

4.1.1. Conversion of Cross Section. The cross section of the concrete cable duct can be converted into an I-shaped cross section regardless of the cushion layer. As shown in Table 2, $\mathrm{B}, \mathrm{H}$, and $\mathrm{D}$ represent the width of the cross section, the height of the cross section, and the diameter of the HDPE conduits, respectively. As shown in Figure 16, by the rule of equal area and moment of inertia, the round hole can be converted into a rectangular hole. The dimensions of the I-shaped section can be calculated by the following formulas. Table 4 shows the result:

$$
\begin{aligned}
h_{r} & =\frac{\sqrt{3}}{2} D, \\
b_{r} & =\frac{\sqrt{3} \pi}{6} D, \\
b_{f} & =B, \\
h & =H, \\
h_{f} & =e-0.5 h_{r}, \\
b & =b_{f}-n b_{r}, \\
h_{w} & =h-2 h_{f} .
\end{aligned}
$$

4.1.2. Theoretical Calculation. For the calculation of the I-shaped section, the code gives the solution. First, determine whether the height of the compression zone is within the flange by the following formulas:

$$
\begin{aligned}
& F_{s}=f_{y} A_{s}, \\
& F_{c}=\alpha_{1} f_{c} b_{f}^{\prime} h_{f}^{\prime}, \\
& F_{s}<F_{c} .
\end{aligned}
$$

For $\mathrm{A} 1$ and $\mathrm{B} 1$.

Hence, the compression zones of $\mathrm{A} 1$ and $\mathrm{B} 1$ are within the flange. Second, the bending capacity of the I-shaped section is calculated by the following formula. Table 5 shows the result. The theoretical bending capacities of A1 and B1 are $195.8 \mathrm{kPa}$ and $67.7 \mathrm{kPa}$, respectively: 

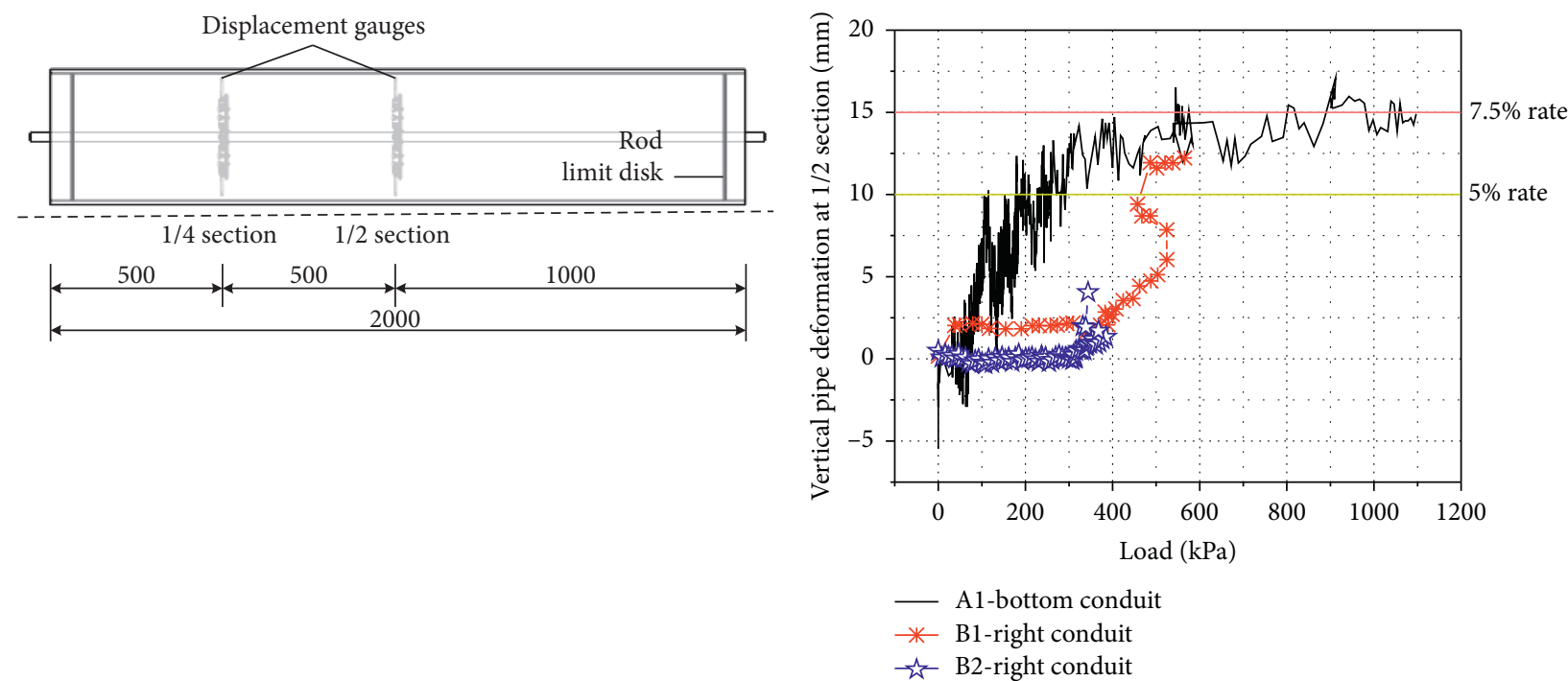

(a)

(b)

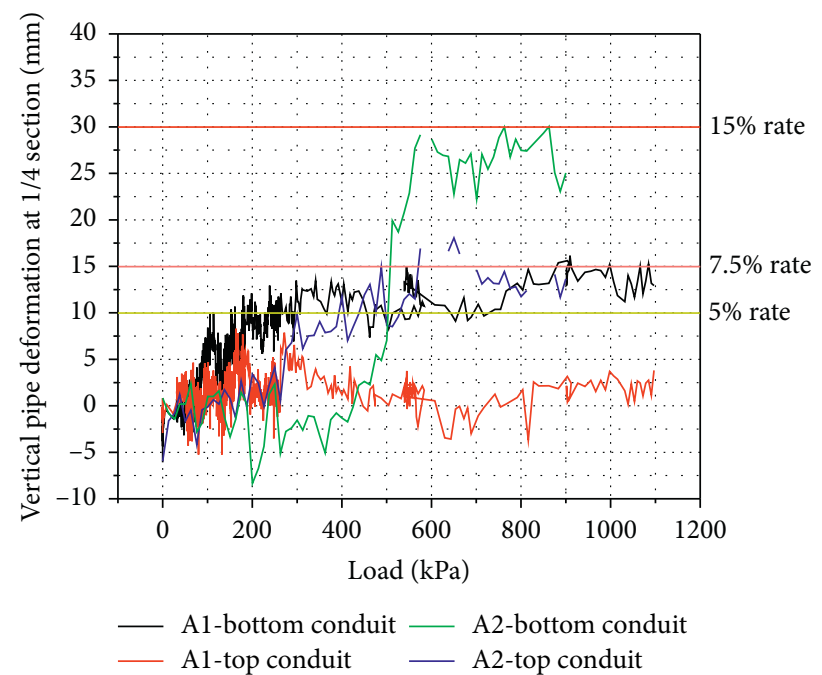

(c)

Figure 15: Vertical deformation of HDPE conduits. (a) Measuring points of HDPE conduits: (b) 1/2 section and (c) 1/4 section.
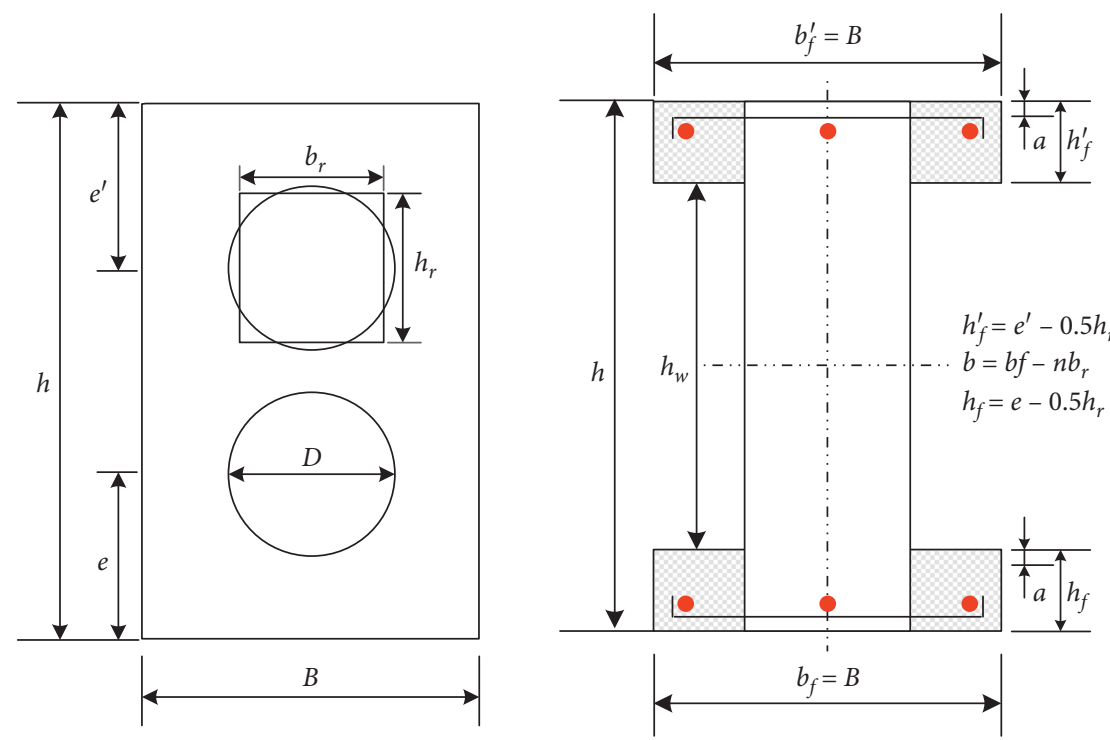

Figure 16: Equivalent I-shaped cross section of the concrete cable duct. 
TABLE 4: Dimensions of I-shaped section (millimeters).

\begin{tabular}{lccccccccc}
\hline Specimen & $n$ & $h_{r}$ & $b_{r}$ & $b_{f}$ & $h$ & $e$ & $h_{f}$ & $b$ & $h_{w}$ \\
\hline A1 & 2 & 181.3 & 173.2 & 400 & 650 & 200 & 113.4 & 218.7 & 423.2 \\
B1 & 1 & 181.3 & 173.2 & 650 & 400 & 200 & 113.4 & 287.4 & 173.2 \\
\hline
\end{tabular}

Notes. $n$ : number of conduits along the height; $h_{r}$ : height of equivalent rectangle; $b_{r}$ : width of equivalent rectangle; $b_{f}$ : width of flange; $h$ : height of cross section; $e$ : distance between the center of hole and the lower edge; $h_{f}$ : height of lower flange; $b$ : width of web; $h_{w}$ : height of web.

$$
\begin{aligned}
h_{0} & =H-a_{s}, \\
x & =\frac{f_{y} A_{s}}{\alpha_{1} f_{c} b_{f}^{\prime}}, \\
M_{u} & =f_{y} A_{s}\left(h_{0}-\frac{x}{2}\right), \\
P & =\frac{4 M_{u}}{\mathrm{AL}} .
\end{aligned}
$$

4.1.3. Comparison. The bending capacities of $\mathrm{A} 1$ and $\mathrm{B} 1$ in the experiment are $1275 \mathrm{kPa}$ and $450 \mathrm{kPa}$, respectively. However, the theoretical bending capacities of A1 and B1 are $195.8 \mathrm{kPa}$ and $67.7 \mathrm{kPa}$, respectively, which are much lower than the experimental values. There may be two reasons for this result. The first reason may be that the contribution of HDPE conduits to the bending capacity of the specimens is not taken into consideration. The second reason may be that the soil shared part of the upper load, and the subgrade reaction increased during the compaction of the soil, which indirectly improved the bending capacity of the specimens.

\subsection{Allowable Deformation Rate of Conduit Vertical} Diameter. Because there is no code for the concrete cable duct given the regulations for the deformation of HDPE conduits, the code [21] for the polyethylene drainage pipe is taken as the reference. The HDPE conduits are made of HPDE, which is the same as the drainage pipes. The drainage pipes are steel-reinforced, spiral-wound, and buried underground, while the HDPE conduits of the cable duct banks are covered by reinforced concrete. Furthermore, the minimum burial depths of the HDPE conduits and the drainage pipes are $0.9 \mathrm{~m}$ and $0.7 \mathrm{~m}$, respectively. Therefore, it can be inferred that the HDPE conduits are under better protection.

Considering the factors mentioned above, it is reasonable to set a relatively larger allowable deformation rate for the HDPE conduits. The code [21] gives 5\% as the allowable deformation rate. The analysis in Section 3.4 shows that $5 \%$, $7.5 \%$, and $15 \%$ are typical deformation rates for HDPE conduits. The analysis in Sections 3.3.1 and 3.4 shows that when the deformation rates of A-type bottom conduits reach $5 \%$, cracks start to appear on the cover concrete; when the rate exceeds $7.5 \%$, A-type specimens approach the failure load. Moreover, the deformation rate of the bottom conduit is larger than that of the top conduit.

4.3. Suggestions for Monitoring Indexes and Control Standards. Several suggestions for the monitoring indexes and control standards can be obtained from the analysis above.

(1) By the analysis in Sections 3.1 and 3.2, the midspan deflections of $\mathrm{A} 1, \mathrm{~A} 2$, and $\mathrm{B} 2$ are within a range of $60 \mathrm{~mm} \sim 80 \mathrm{~mm}$, and the soil pressure at the midspan bottom of the four specimens is within a range of $140 \mathrm{kPa} \sim 160 \mathrm{kPa}$. The soil conditions are consistent throughout the experiment. It can be inferred that reinforcements and section height have little effect on the midspan deflection and the soil pressure. Furthermore, the soil condition may be the key factor. Therefore, the soil condition should be considered in the monitoring indexes.

(2) The behaviors of the damage pattern are as follows: a small number of cracks appear on the cover concrete, and one main crack appears at the midspan, which is similar to that of the simply supported beams; a steep increase appears in the strain of the cover concrete and the stress of the steel bars and conduits. In conclusion, the damage pattern may be considered brittle damage. However, yield stages appear in the load-displacement curve and soil pressure evolution curve, which corresponds to ductile damage. The reason may be that the compaction of soil is a relatively long process. Thus, electrical duct banks should be monitored continuously, and it is recommended to take the relative magnitudes and the evolution trends as the control standards rather than the absolute magnitudes of evolution.

(3) The analysis in Section 3.3.3 shows that HDPE conduits serve as rebars with respect to the cover concrete and that the stresses of different measuring points on the same conduit are close. Furthermore, the stresses of the conduits on the same row are close. Therefore, measuring points should be arranged on a certain conduit of each row. In practical applications, at least one conduit in each row should be reserved for monitoring according to the on-site situation.

(4) Generally, the space required for high-voltage cables with an outer diameter of $110 \mathrm{~mm}$ is 1.5 times the outer diameter, which is $165 \mathrm{~mm}$. However, the inner diameter of the conduit is $180 \mathrm{~mm}$. Thus, for the normal operation of high-voltage cables, the allowable deformation of the conduit cannot exceed $15 \mathrm{~mm}$, which is $7.5 \%$ of the outer diameter. Considering the above analysis and the analysis in Section $4.2,5 \%$ and $7.5 \%$ can be taken as the deformation rates of the ultimate states of serviceability and bearing capacity, respectively. 
TABle 5: Parameters in formula (6).

\begin{tabular}{lcccccccc}
\hline Specimen & $A_{s}\left(\mathrm{~mm}^{2}\right)$ & $\alpha_{1}$ & $x(\mathrm{~mm})$ & $h_{0}(\mathrm{~mm})$ & $M_{u}(\mathrm{kN} \cdot \mathrm{m})$ & $A\left(\mathrm{~m}^{2}\right)$ & $L(\mathrm{~m})$ & $P(\mathrm{kPa})$ \\
\hline A1 & 339 & 1.0 & 28.1 & 600 & 66.5 & 0.8 & 1.7 \\
B1 & 327 & 1.0 & 16.7 & 350 & 37.4 & 1.3 & 1.7 & 67.7 \\
\hline
\end{tabular}

Notes. $A_{s}$ : area of tension bars; $\alpha_{1}$ : ratio of the magnitude of concrete rectangular stress diagram in compression zone to the design value of concrete axial compressive strength; $x$ : height of compression zone; $h_{0}$ : effective height; $M_{u}$ : bending capacity of normal section; $A$ : area of top surface; $L$ : distance between two hinge supports; $P$ : theoretical bending capacity of specimens.

Furthermore, the deformation rate of the bottom conduit is larger than that of the top conduit. Hence, measuring points should be arranged on the conduits of the bottom row in practical applications.

(5) For shield tunnels, the longitudinal deformation is generally described by the curvature radius. Because the structures of the underground electrical duct banks and the shield tunnels are similar in the longitudinal direction, the longitudinal deformation of the underground electrical duct bank can be described by the curvature radius. However, an underground electrical duct bank is generally a castin-place reinforced concrete structure without joints, and its damage pattern is brittle, which is different from that of a shield tunnel. Therefore, it is recommended to take $20 \mathrm{~mm}$ of the midspan deflection as the threshold. With respect to the $20 \mathrm{~mm}$ midspan deflection, the curvature radius $R$ is $18063 \mathrm{~m}$. In summary, $R \min =18000 \mathrm{~m}$ can be taken as the threshold of the longitudinal curvature radius for an underground electrical duct bank.

From the perspective of safety and convenience, it is recommended to use the stress and deformation rate of HDPE conduits to formulate the monitoring indexes and control standards for electrical duct banks.

\section{Conclusion}

This paper presented an experimental investigation of the bending behaviors of concrete-encased underground electrical duct banks. This study is aimed at determining a set of thresholds for electrical duct banks. The experimental study was realized in a soil box using an advanced monitoring device, which can measure the diameter change of HDPE conduits. In addition, the HDPE conduit played a critical role in the improvement of the bending capacity of the electrical duct bank. Experiments were conducted on four specimens: two A-type specimens $(H=650 \mathrm{~mm})$ and two B-type specimens $(H=400 \mathrm{~mm})$. Based on this study, the following conclusions can be drawn:

(a) Reinforcements and section height have little effect on the midspan deflection and the soil pressure. The soil condition should be considered in the monitoring indexes.

(b) HDPE conduits and underlying soil have a positive effect on improving the bending capacity of electrical duct banks. (c) The damage pattern of an electrical duct bank is brittle damage. Electrical duct banks should be monitored continuously, and it is recommended to take the relative magnitudes and evolution trends as the control standard.

(d) Measuring points of stress and deformation rates of HDPE conduits should be arranged on each row and the bottom row, respectively.

(e) Deformation rates of $5 \%$ and $7.5 \%$ can be taken as the thresholds for HDPE conduits with respect to the serviceability ultimate state and the bearing capacity ultimate state, respectively.

(f) $\mathrm{Rmin}=18000 \mathrm{~m}$ can be taken as the threshold of the longitudinal curvature radius for the underground electrical duct bank.

In conclusion, it is recommended to use the stress and deformation rate of HDPE conduits to formulate monitoring indexes and control standards for electrical duct banks.

To quantify the contribution of the HDPE conduits and the subgrade reaction to the bending capacity of the specimens, three experiments are designed:

(a) Specimens A1 and B1 are simply supported, and a distributed surface load is monotonically applied.

(b) Specimens without HDPE conduits are monotonically subjected to a distributed surface load under the same soil conditions as the experiment mentioned above.

(c) Specimens A1 and B1 apply a distributed surface load monotonically under different soil conditions.

Furthermore, the authors will carry out studies on the influence of cyclic or vibration loadings (triggered by driving or earthquakes, etc.) on mechanical behavior in future research.

\section{Data Availability}

The data used to support the findings of this study are included within the article.

\section{Conflicts of Interest}

The authors declare that there are no conflicts of interest regarding the publication of this paper. 


\section{Acknowledgments}

This work was funded by the National Natural Science Foundation of China (nos. 51678248, 51878296, and 51808230) and the Technical Projects of China Southern Power Grid (no. GD-KJXM-20172975).

\section{References}

[1] U. K. National Grid, "New essential infrastructure: london power tunnels," 2018, https://www.nationalgridet.com/ infrastructure-projects/london-power-tunnels.

[2] National Grid UK. Technical Guidance Note 287, Third-party guidance for working near National Grid Electricity Transmission equipment.

[3] J. Yu and Y. Zhou, "Genetic algorithm for reasonable laying length of power cable piping," East China Electric Power, vol. 40, no. 5, pp. 861-863, 2012, in Chinese.

[4] W.-C. Cheng, G. Li, N. Liu, J. Xu, and S. Horpibulsuk, "Recent massive incidents for subway construction in soft alluvial deposits of Taiwan: a review," Tunnelling and Underground Space Technology, vol. 96, Article ID 103178, 2020.

[5] K. Wu and Z. Shao, "Visco-elastic analysis on the effect of flexible layer on mechanical behavior of tunnels," International Journal of Applied Mechanics, vol. 11, no. 3, Article ID 1950027, 2019.

[6] L. J. Kelly, "Cable ampacity practice for low voltage and medium voltage power cables," in Proceedings of the IEEE Textile Industry Technical Conference IEEE, Greenville, SC, USA, May 1988.

[7] D. Nagley and R. Nease, "Thermal characteristics of two types of concrete conduit installations," IEEE Transactions on Power Apparatus and Systems, vol. PAS-86, no. 9, pp. 1117-1124, 1967.

[8] M. Kellow, "A numerical procedure for the calculation of the temperature rise and ampacity of underground cables," IEEE Transactions on Power Apparatus and Systems, vol. PAS-100, no. 7, pp. 3322-3330, 1981.

[9] M. Kellow, H. St-Onge, and R. Mier-Maza, "Thermal behaviour of an underground duct bank cable system under normal and forced cooling conditions," in Underground Cable Thermal Backfill, pp. 192-205, Pergamon Press, Oxford, UK, 1982.

[10] M. Kellow, "Experimental investigation of the ampacity of distribution cables in a duct bank with and without forced cooling," IEEE Transactions On Power Apparatus \& Systems, vol. PAS-100, no. 7, pp. 3274-3283, 2007.

[11] M. El-Kady and D. Horrocks, "Extended values for geometric factor of external thermal resistance of cables in duct banks," IEEE Transactions on Power Apparatus \& Systems, vol. PER104, no. 8, pp. 1958-1962, 1988.

[12] E. Bascom, "Magnetic field management considerations for underground cable duct bank," in Proceedings of the Transmission \& Distribution Conference \& Exhibition IEEE, Atlanta, Georgia, May 2006.

[13] C. C. Hwang, "Calculation of thermal fields of underground cable systems with consideration of structural steels constructed in a duct bank," IEE Proceedings-Generation, Transmission and Distribution, vol. 144, no. 6, pp. 541-545, 2002.

[14] B. Malmedal, C. Bates, D. Cain et al., "Engineering the thermal resistivity of concrete duct banks," in Proceedings of the Cement Industry Conference IEEE, Dallas, TX, USA, May 2015.
[15] Z. D. Abootorabi and V. Behrooz, "Multi objective self adaptive optimization method to maximize ampacity and minimize cost of underground cables," Journal of Computational Design \& Engineering, vol. 5, no. 4, pp. 401-408, 2018.

[16] P. Ocoń, P. Cisek, and M. Rerak, "Thermal performance optimization of the underground power cable system by using a modified Jaya algorithm," International Journal of Thermal Sciences, vol. 123, pp. 162-180, 2018.

[17] K. Charerndee, R. Chatthaworn, P. Khunkitti, A. Kruesubthaworn, A. Siritaratiwat, and C. Surawanitkun, "Effect of concrete duct bank dimension with thermal properties of concrete on sensitivity of underground power cable ampacity," in Proceedings of the 18th International Symposium on Communications and Information Technologies (ISCIT), Bangkok, Thailand, September 2018.

[18] C. Liu and J. Ying, "Experimental study on flexural performance of concrete cable duct reinforced with glass fiber reinforced polymer bars," Fuhe Cailiao Xuebao/Acta Materiae Compositae Sinica, vol. 35, no. 1, pp. 70-80, 2018.

[19] C. Liu, J. Wang, Y. Chen et al., "Shear bearing capacity of concrete cable duct reinforced with GFRP bars," Fuhe Cailiao Xuebao/Acta Materiae Compositae Sinica, vol. 35, no. 12, pp. 3331-3341, 2018.

[20] Y. Wang and J. Guo, "Settlement and damage analysis of working shaft for underground high-voltage electricity cables," IOP Conference Series Earth and Environmental Ence, vol. 304, Article ID 32063, 2019.

[21] China Association for Engineering Construction Standardization, Technical Specification for Steel-Reinforced Spirally Wound Polyethylene of Drainage Pipeline Engineering (CECS 248:2008), China Planning Press, Beijing, China, 2008, in Chinese.

[22] Ministry of Construction of the People's Republic of China, Code for Design of Concrete Structures (GB 50010-2010), China Architecture \& Building Press, Beijing, China, 2010, in Chinese. 